\title{
International Safeguards for a Modern MOX Fuel Fabrication Facility
}

K. K. S. Pillay

D. Stirpe

R. R. Picard

\section{DISCLAIMER}

\begin{abstract}
This report was prepared as an account of work sporsored by an agen:y or the United States Government. Neither the United States Government nor any agency thereof, nor any of their employees, makes any warranty, express or implied, or assumes any legal liability or responsibility for the accuracy, completeness, or usefulness of any information, apparatus, product, or process disclosed, or represents that its use would not infringe privately owned rights. Reference herein to any specific commercial product, process, or service by trade name, trademark. manufacturer, or otherwise does not necessarily constitute or imply its endorsement, recommendation, or favoring by the United States Government or any agency thereof. The views and opinicns of authors expressed herein do not necessarily state or reflect those of the United States Government or any agency thereof.
\end{abstract}

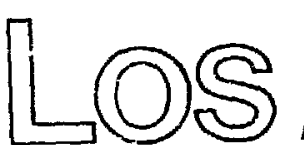




\section{EXECUTTVE SUMMARY}

This report, prepared for the Office of Safeguards and Security of the Department of Energy, addresses safeguards issues relevant to materials accountancy and International Atomic Energy Agency (IAEA) verification activities at a modern mixed-oxide (MOX) fuel fabrication facility under IAEA safeguards. This work is an extension of an earlier study done by the Safeguards Systems Group at the Los Alamos National Laboratory during FY'85 under the sponsorship of the U.S. Arms Control and Disarmament Agency. The earlier study was limited to identifying key elements of IAEA safeguards at a modern MOX fuel fabrication facility that could detect abrupt diversions. The present work addresses several issues of primary importance to materials accountancy and IAEA verification of the operator's mate-* rials balances and physical inventories.

This MOX fuel fabrication plant is a bulk-handling facility where large quantities of plutonium are handled in chemical forms that are easily separated and converted into materials directly useful for nuclear explosives. Several IAEA member states are adopting state-of-the-art fuel-cycle technologies in newly constructed MOX fuel fabrication facilities. The facility design considered here is intended to enhance safeguards effectiveness at such a facility; it incorporates new technologies, remote/automated process operations, and features to augment near-real-time materials accountancy. This reference facility is a large-throughput plant (2.2 Mt $\mathrm{Pu} / \mathrm{yr}$ ) with extensive storage facilitie: for both feed materials and products. The two process lines at the plant can produce fuel assemblies for both fast breeder reactors (FBRs) and advanced thermal light-water reactors (ATRs).

In this report, a detailed process design is presented, along with the analysis results of materials accountancy based on both abrupt and protracted diversion scenarios. Appendixes A through D discuss assumptions and methods used in our analyses. In addition, we present sampling plans for IAEA attributes/variables verification and calculations of $\sigma_{\left(M U F^{*}-D\right)}$, where MUF ${ }^{*}$ is an incomplete MUF (materials unaccounted for), and of corresponding detection probabilities for specified material-loss scenarios and two IAEA resource allocations. Although generic aspects of (MUF-D) have been discussed in the literature, to our knowledge no detailed simulation illustrating (MUF-D) behavior (as described in Appendix D) has been undertaken. 
A detailed analysis of the detection sensitivity of materials accountancy was conducted; the variance contributions for the operator's monthly materials balance closings at the process materials balance area (MBA) have a standard deviation of $1.446 \mathrm{~kg}$ of plutonium, which represent about $0.8 \%$ of the throughput or about $0.2 \%$ of the plutonium inventory during steady-state operation. Current practices at some fuel fabrication facilities, where the facility operators use results of high-quality chemical analyses of fuel pellets in accounting for fuel pins and fuel assemblies, would show a more optimistic $\sigma$ value of $0.9 \mathrm{~kg}$ of plutonium for this process MBA.

In addition, we quantified how sensitive the materials accounting system is to protracted losses of materials, assuming losses spread evenly over several inventory periods during a year. These sensitivities were calculated assuming that the measurement instruments are calibrated monthly. For a $5 \%$ false-alarm rate, detection probabilities exceed $98 \%$ for all of the loss scenarios considered. The results of the ${ }^{\sigma}\left(\right.$ MUF $\left.^{*}-D\right)$ Calculations for abrupt diversions indicate that, if about $\$ 35,000$ per month is spent on inspections, detection probabilities for most of the falsification scenarios considered exceed $50 \%$.

During this investigation, we have considered only uniform fuel-pin compositions in fuel assemblies and simple diversion scenarios to demonstrate the value of materials accountancy and verification activities. Examination of nonuniform fuelassembly designs at an operating facility, more-complex diversion scenarios, optimal allocation of resources for a facility-specific inspection, and an extension of $\sigma_{\text {(MUF-D) }}$ calculations to protracted diversions are logical extensions of this investigation. 


\section{CONTENTS}

ABSTRACT

I. INTRODUCTION 2

II. THE REFERENCE MOX FUEL FABRICATION FACILITY 4

A. Fuel Fabrication 5

B. Facility Operation 5

C. Materials Balance Areas 7

D. Flow and Distribution of Materials 9

III. DETECTION SENSITIVITY OF THE OPERATOR'S MATERIALS ACCOUNTING SYSTEM $\quad 12$

A. Key Measurement Points for MBA-2 12

B. Detection Probability for MBA-2 (Abrupt Diversion) 15

C. Detection Probability for MBA-2 (Protracted Diversion) 19

IV. IAEA INSPECTOR VERIFICATTON ACTTVITTES 23

A. Storage Vaults--Verification by Attributes Sampling 25

B. Transfers and Inventories for MBA-2--Verification by Attributes/Variables Sampling 25

C. Containment/Surveillance Measures 28

V. VERIFICATION BY CALCULATION OF (MUF-D) AND DETECTION PROBABILITY 29

A. Determination of Inspector's Sample Sizes 30

B. $\left(\right.$ MUF $\left.^{*}-\mathrm{D}\right)$ and Detection Probabilities for Different Loss Scenarios

VI. DISCUSSION AND CONCLUSIONS

ACKNOWLEDGMENTS

REFERENCES $\quad 41$

APPENDIX A. MBA STRUCTURE OF THE MOX FUEL FABRICATION LINES

I. MOX STORAGE VAULT (MBA-1)

II. MOX FUEL FABRICATION LINES (MBA-2) 45

III. FUEL-ASSEMBLY STORAGE VAULT (MBA-3) 48

IV. MOX FACILITY DESIGN CAPACITY 48

APPENDIX B. EXAMPLE VARIANCE CALCULATIONS 50

APPENDIX C. SEQIJENTIAL ANALYSIS OF MATERIALS BALANCES 52

I. ERROR PROPAGATION 52

II. NOTATION AND DEVELOPMENT

III. SEQUENTIAL TESTING

REFERENCES $\quad 56$ 


\section{CONTENTS (cont)}

APPENDIX D. BEHAVIOR OF THE (MUF-D) STATISTIC

I. THE SAMPLING MECHANISM

II. EXTRAPOLATION, GOAL QUANTITIES, AND THE D STATISTIC 60

III. MEASTREMENT ERRORS 63

IV. (MUF ${ }^{*}$-D) FOR THE MOX LINE 64

V. DIVERSION STRATEGIES

$\begin{array}{ll}\text { REFERENCES } & 67\end{array}$

\section{TABLES}

I. Assumed Distribution of Plutonium at the Processing Areas of the MOX Facility During Normal Operations

II. Operator's Measurement Standard Deviations for Determination of Plutonium Concentration

III. Operator's Mass Measurement Standard Deviations

IV. Variance Contrisutions at the Key Measurement Points for a 21-Day Accounting Period

V. Detection Probabilities for MBA-2 for a Detection Sensitivity of $8 \mathrm{~kg}$ of Plutonium

V. Detection Probabilities for Various Loss Scenarios

VII. Key Measurement Points and Verification Activities

VIII. Attributes Sample Sizes for $95 \%$ and $75 \%$ Detection Probabilities for Items in Storage Vaults

LX. Attributes and Variables Sample Sizes for $95 \%$ and $75 \%$ Detection Probabilities for MBA-2 Strata Containing $8 \mathrm{~kg}$ of Plutonium or More

X. Assumed Inspector Cost Per Measurement

XI. Inspector's Sample Sizes for 11 MOX-Line Strata for Two Values of Available Resources

XII. Falsification Scenarios and Detection Probabilities

A-I. Capacity and Average Inventory of Each MBA 


\section{FIGURES}

1. The position of the MOX fuel fabrication facility in the commercial nuclear fuel cycle.

2. Major processing steps in MOX fuel fabrication.

3. MBA structure of the MOX fuel fabrication facility and material flow within the process MBA.

4. Material flow paths within one of the MOX fuel fabrication lines.

5. Resources available vs $\sigma\left(M_{U}{ }^{*}-D\right)$.

A-1. Major MBAs of the MOX fuel fabrication facility and subdivisions of process MBA-2.

A-2. Approximate material transfers per day across the boundaries of MBA-2-1.

A-3. Approximate material transfers per day across the boundaries of MBA-2-2.

A-4. Approximate material transfers per day across the boundaries of MBA-2-3.

D-1. Histogram for the distribution of the number of falsified items among the inspector's samples of 8 items when 500 of the 1000 items are falsified.

D-2. Histogram for the distribution of the number of falsified items arnong the inspector's samples of 8 items when 50 of the 1000 items are falsified.

D-3. Histogram for the distribution of the number of falsified items among the inspector's samples of 8 items when 950 of the 1000 items are falsified.

D-4. Histogram for the distribution of the number of falsified items among the inspector's samples of 8 items when 200 of the 1000 items are falsified.

D-5. Histogram for the distribution of the D statistic given the scenario of Fig. D-1 when there are no measurement errors.

D-6. Histogram for the distribution of the D statistic given the scenario of Fig. D-2 when there are no measurement errors.

D-7. Histogram for the distribution of the D statistic given the scenario of Fig. D-3 when there are no measurement errors. 


\section{FIGURES (cont)}

D-8. Histogram for the distribution of the D statistic given the scenario of Fig. D-4 when there are no measurement errors.

62

D-9. Histogram of the observed $\left(M U F^{*}-D\right)$ for scenario 3 at $\$ 10,000 /$ month (see Table XII).

D-10. Histogram of the observed $\left(M_{U} F^{*}-D\right)$ for scenario 6 at $\$ 35,000 /$ month (see Table XII).

D-11. Histogram of the observed $\left(M U F^{*}-D\right)$ for scenario 7 at $\$ 10,000 /$ month (see Table XII). 


\title{
INTERNATIONAL SAFEGUARDS FOR A MODERN MOX FUEL FABRICATION FACILITY
}

\author{
by
}

K. K. S. Pillay, D. Stirpe, and R. R. Picard

\begin{abstract}
Bulk-handling facilities that process plutonium for commercial fuel cycles offer considerable challenges to nuclear materials safeguards. Modern fuel fabrication facilities that handle mixed oxides of plutonium and uranium (MOX) of ten have large inventories of special nuclear materials in their process lines and in storage areas for feed and product materials. In addition, the remote automated processing prevalent at new MOX: facilities, which is necessary to minimize radiation exposures to personnel, tends to limit access for measurements and inspections. The facility design considered in this study incorporates all these features as well as state-of-the-art measurement technologies for materials accounting. Key elements of International Atomic Energy Agency (IAEA) safeguards for such a fuel-cycle facility have been identified in this report, and several issues of primary importance to materials accountancy and LAEA verifications have been examined. We have calculated detection sensitivities for abrupt and protracted diversions of plutonium assuming a single materials balance area for all processing areas. To help achieve optimal use of limited IAEA inspection resources, we have calculated sampling plans for attributes/variables verification. In addition, we have demonstrated the usefulness of calculating $\sigma_{(M U F-D)}$ and detection probabilities corresponding to specified material-loss scenarios and resource allocations. The data developed and the analyses performed during this study can assist both the facility operator and the IAEA in formulating necessary safeguards approaches and verification procedures to implement international safeguards for special nuclear materials.
\end{abstract}




\section{INTRODUCTION}

In the commercial nuclear fuel cycle, bulk-handling facilities that store large quantities of plutonium and those that fabricate fuel assemblies from mixed oxides of uranium and plutonium (MOX) are some of the most sensitive facilities from a safeguarás point of view. Because MOX facilities have large inventories of nuclear material in a form that would be attractive to a divertor, they require frequent inspections and stringent safeguards to detect both abrupt and protracted diversions.

The objective of this task is to assist the Depariment of Energy (DOE) and other U.S. government agencies in formulating safeguards appoaches necessary for achieving intarnational safeguards objectives for MOX fuel fabrication facilities. The datit developed and the analyses performed in this study can assist both the facility operator and the International Atomic Energy Agency (LAEA) in formulating necessary safeguards approaches ard verification procedures to implement international safeguards based on INFCIRC/153. ${ }^{1}$ This work is an extension of an earlier study by the Safeguards Systems Group at Los Alamos to identify the key elements of IAEA safeguards for a modern MOX fuel fabrication facility against abrupt diversions. ${ }^{2}$ In this work, we use the generic design features of a modern MOX fuel fabrication facility to identify safeguards issues and to determine the safeguards measures and inspection methods that detect both abrupt and protracted diversion of nuclear materials from such a facility on a timely basis.

The reference plant considered for this study is a modern fuel fabrication facility producing fuel for both fast breeder reactors (FBRs) and advanced thermal light-water reactors (ATRs). This is a fully automated modern plant located adjacent to a fuel reprocessing and conversion plant. All plutonium inputs to this MOX facility originate from a nearby LAEA safeguarded co-conversion facility, and these shipments in the form of 1:1 MOX are received as items transfarred under IAEA seals.

This MOX fuel fabrication facility has large inventories of both feed and product materials on site. The design and operation of this facility allows the operator to retrieve and store most of the in-process materials as measured items during inventory. We also assumed that this facility uses remote operation techniques, modern nondestructive assay (NDA) and analytical instrumentation, computerized near-real-time materials accounting, and state-of-the-art materials control and physical protection. Additional details about this reference facility are presented in Sec. II of this report. 
Because of the at smated fuel fabrication and limited access to process areas, some new appoaches to safeguards and IAEA inspections are necessary. For reporting inventory differences to the IAEA, the whole plant is considered as a single materials balance area $(\mathrm{MBA})$, thus minimizing the number of transfers the State must report to the IAEA and the number of verifications the IAEA must make during inspections.

Based on this assumed MBA structure, we calculated the detection sensitivities for both abrupt and protracted diversion that are presented in Sec. III; additional details are given in Appendix C. Procedures for accounting for and verification of all stored items and materials in process as well as the complementary containment and surveillance measures, which are considered as key elements of IAEA safeguards at this facility, are detailed in Secs. IV and V. In Sec. V, inspector verification procedures for calculation of $\sigma_{\left(\mathrm{MUF}^{*}-\mathrm{D}\right)}$ and corresponding detection probabilities for specified plutonium-loss scenarios are presented; additional details are given in Appendix D. A detailed description of the MBA structure of the MOX fuel fabrication facility is presented in Appendix A. Appendix B shows two examples of variance calculations used in determining the results reported here. Appendix $C$ presents the details of sequential analysis of materials balances used in the protracted diversion scenarios. The behavior of the (MUF-D) statistic is described in general terms in Appendix D. 


\section{THE REFERENCE MOX FUEL FABRICATION FACILITY}

The reference plant uses MOX to fabricate fuel for FBRs and for plutonium recycle in ATRs. The MOX fuel material consists of a homogeneous mixture of $\mathrm{PuO}_{2}$ and $\mathrm{UO}_{2}$ appropriately processed to produce a true ceramic material and fabricated into fue! elements clad in zircalloy (for thermal reactors) or stainless steel (for FBRs). The position of this fuel fabrication facility in the commercial nuclear fuel cycle is as represented in Fig. 1.

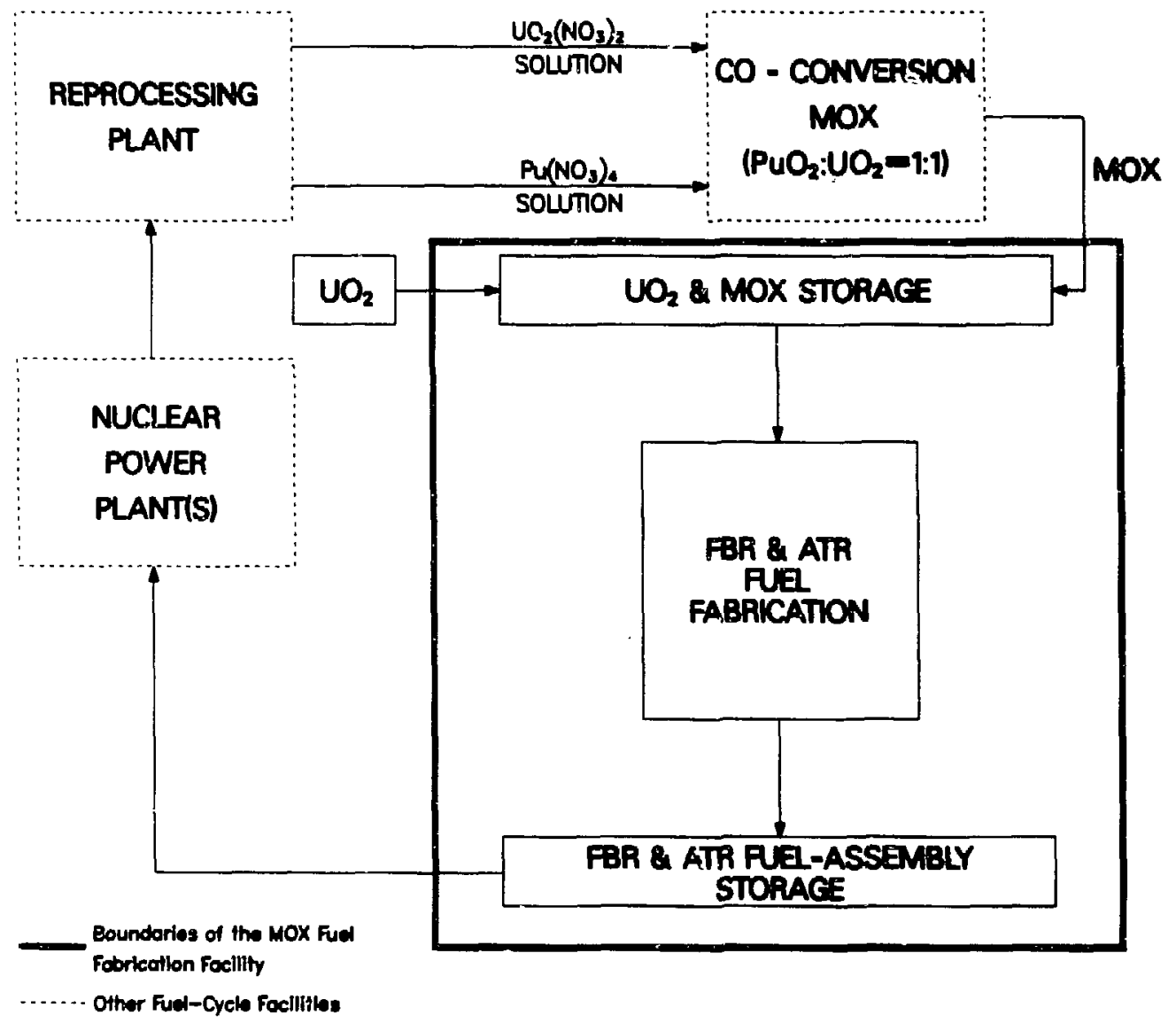

Fig. 1. The position of the MOX fuel fabrication facility in the commercial nuclear Euel cycle. 


\section{A. Fuel Fabrication}

There are two independent process lines to fabricate FBR and ATR fuels. The various process steps involved at both these process lines are similar, but the fuel compositions and fuel-assembly configurations differ. The steps in fabricating MOX fuel assemblies at this facility are shown in Fig. 2. The $\mathrm{UO}_{2}$ used usually originates from a fuel reprccessing plant or from a conversion plant processing natural uranium. Therefore, the isotopic composition of uranium in the $\mathrm{UO}_{2}$ used is approximately the natural abundance of ${ }^{235} \mathrm{U}$.

Properly proportioned mixtures of $1: 1$ MOX and $\mathrm{UO}_{2}$ are first blended and milled to a uniform consistency. Binder materials, which serve to control the final porosity of the pellets, are added to the blended MOX. This mixture is dried, granulated, and screened to retain granules of a certain size range (about 150 to 850 $\mu \mathrm{m})$. These granules are blended with a lubricant before they are formed into pellets in presses operating at about 2 to $4 \times 10^{8} \mathrm{~Pa}$. The binder is removed from the green pellets by heating them in a furnace at $\sim 650^{\circ} \mathrm{C}$ in an atmosphere of argon mixed wiih $\sim 8 \%$ to $10 \%$ of hydrogen. These pellets are sintered in a similar inert reducing atmosphere at $\sim 1600^{\circ} \mathrm{C}$ to $1750^{\circ} \mathrm{C}$.

The sintered pellets are cooled to room remperature in an inert atmosphere of argon. The pellets are then sorted and ground to tolerances in centerless grinding machines to meet the fuel-pellet specifications. The ground pellets are individually inspected before being arranged into pellet stacks. Each pellet stack contains approximately the number of fuel pellets required for a fuel pin. The pellets are outgassed at elevated temperatures to remove final traces of moisture and organic residues before they are loaded into clean cladding tubes with one end-cap welded in place. The loaded tubes are inspected, decontaminated, evacuated, and filled with an inert gas before the second end-cap is welded on. The sealed tubes are leak-tested, radiogaphed, and subjected to fissile loading assay before they are fashioned into fuel pins and fuel assemblies.

\section{B. Facility Operation}

This MOX fuel fabrication facility is an automated production facility that operates for 250 daysiyr (or about 21 working days/calendar month) with an annual throughput of $2.2 \mathrm{Mt}$ of plutonium. All bulk-handling operations involving MOX are carried out in interconnected glove boxes, maintained at a slight negative pressure, with limited personnel access. The elapsed time between the introduction of the feed material and the completion of the fuel assemblies is about 3 to 4 weeks. 


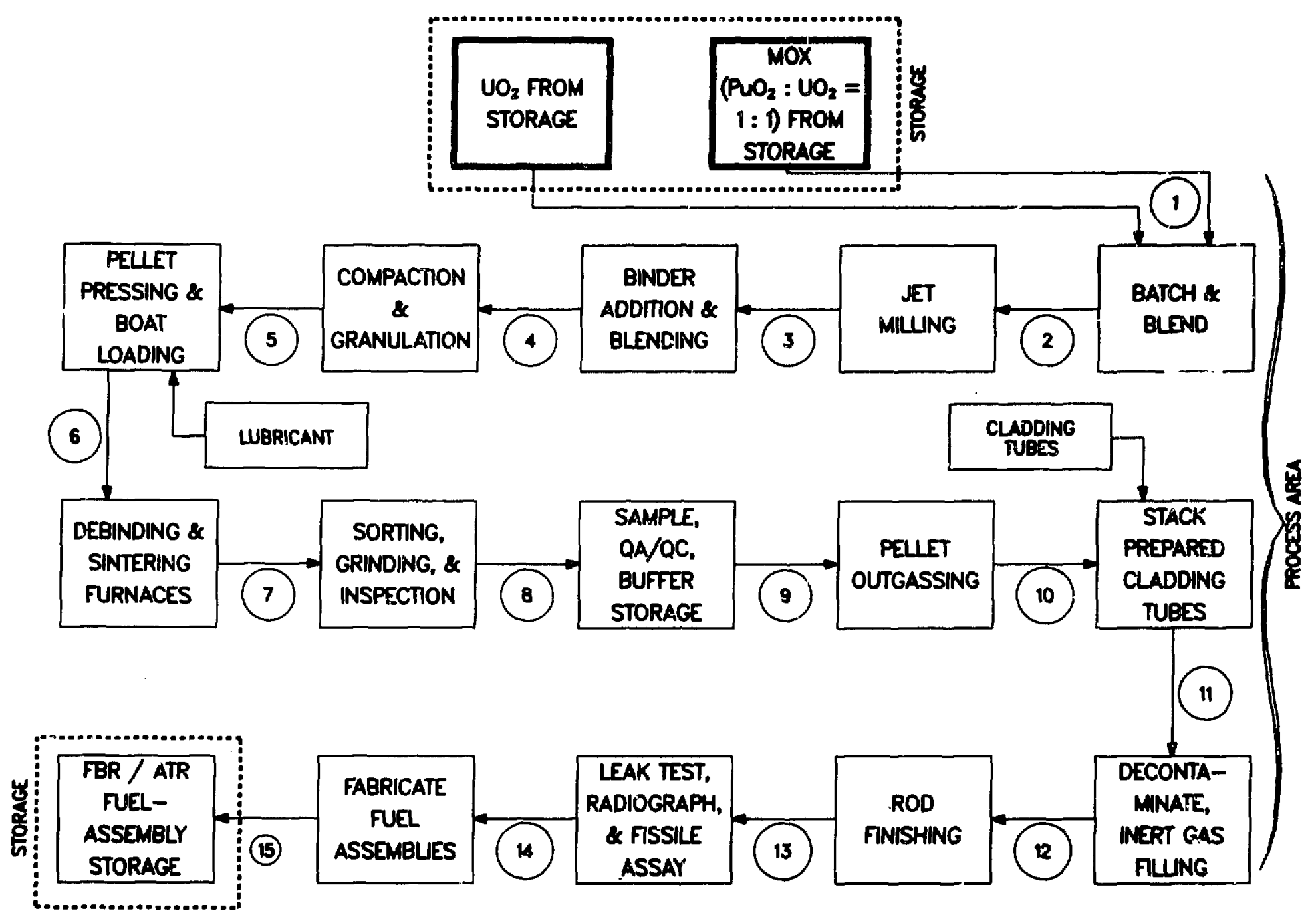

Fig. 2. Major processing steps in MOX fuel fabrication. 
The FBR line recycles $\sim 25 \%$ of its input MOX blend, and the ArR line recycles $\sim 4 \%$ of its blend. This facility produces only a limited amount of scrap that requires processing for recovery. Wastes generated at the analytical laboratory and nonrecoverable scrap generated at the production lines are periodically processed to recover the nuclear materials as MOX. This recovered MOX is regularly fed into the powder-blending stages of the two production lines. Approximately $5 \mathrm{~kg}$ of plutonium annually ends up as miscellaneous, bulky, nonrecoverable waste. Most of this waste is retrievably stored for eventual disposal. We assumed that the residual holdup at this facility is small and that it reaches a steady-state level that averages about $0.4 \mathrm{~kg}$ of plutonium (or about $7 \mathrm{~kg}$ of MOX).

A unique operational feature of this facility is that there are built-in provisions to remove and store all in-process materials, except those in furnaces, after each day's work period. There are interim storage areas for in-process materials and for ciean scrap in both the process MBAs. The in-process materials are measured at the end of each day and temporarily stored in containers as items until the next working day. As materials are transferred into and out of the interim storage, they are identified by scanning a unique number etched on the container using an optical monitor. The contents of these containers are weighed, and an attribute is measured using facility-installed NDA equipment. All this information is entered into the facility's near-real-time accounting (NRTA) computer.

During monthly materials balance closings, and/or IAEA inspections, the facility operates on its normal schedule except for running out all the materials in the furnaces. However, a few days before the physical inventory verification, which we assumed occurs semiannually, the plant is shut down completely to run out all the materials in furnaces and to carry out cleanout operations necessary to reduce inprocess holdup.

\section{Materials Balance Areas}

Fuel fabrication facilities in general are divided into several MBAs for materials control and accountancy purposes. ${ }^{3}$ Most of the existing MOX facilities with only one process line are divided into three or more MBAs. Following the criteria proposed in INFCIRC $/ 153,{ }^{1}$ our reference MOX fabrication facility with two process lines is divided into three MBAs, as shcwn in Fig. 3. MBA-1 is a feed receiving/ storage vault where materials are always transferred as items. The two process lines and the processing area for recovering plutonium and uranium from recoverable waste streams from all areas of the plant are designated as MBA-2. Detailed 


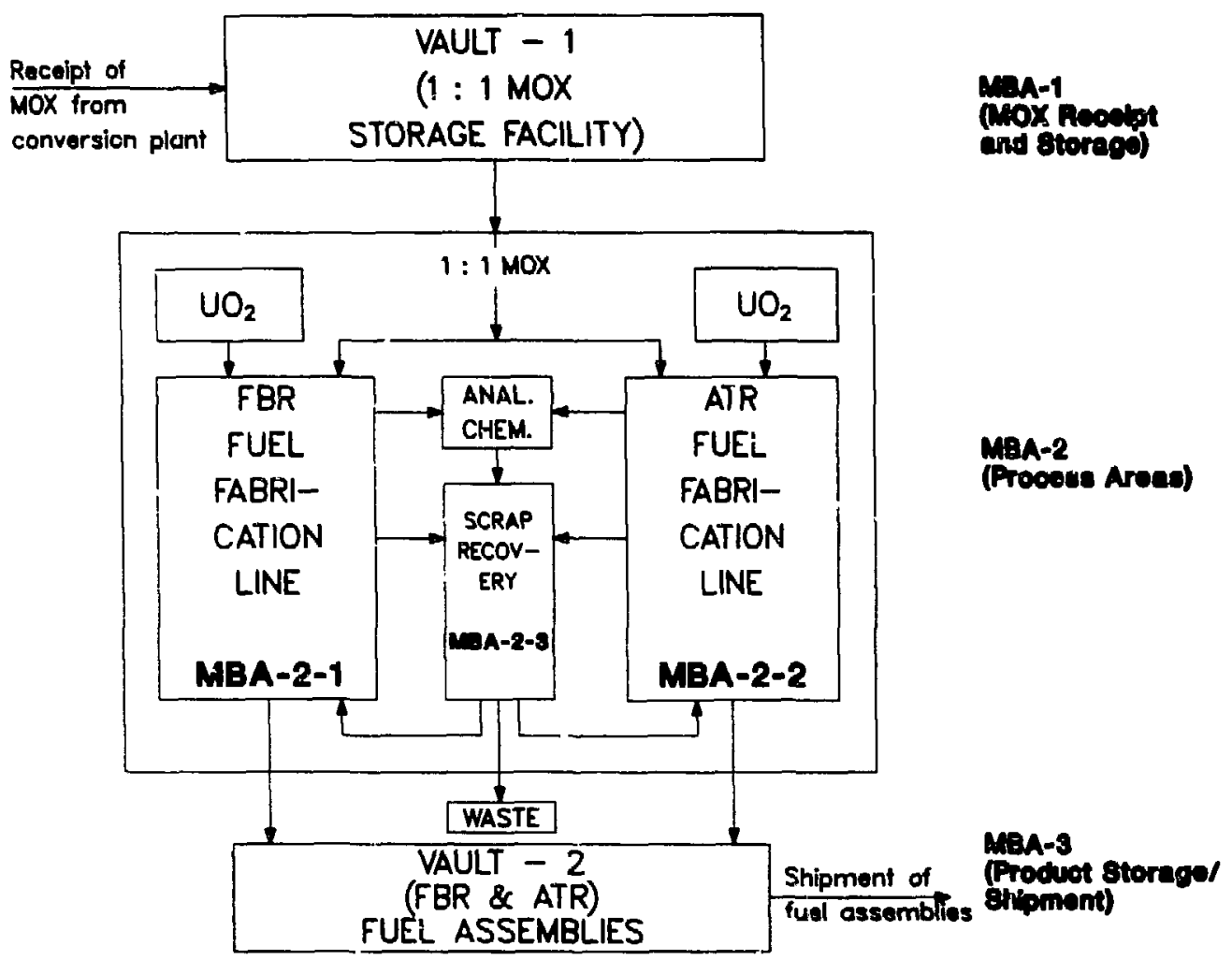

Fig. 3. MBA structure of the MOX fuel falbrication facility and mateifial flow within the process MBA.

material floa:s through different parts of MBA-2 are described in Appendix A. MBA-3 is another storage vault where fully fabricated fuel assemblies are stored with tamper-resistant seals. Fuel assemblies are shipped out to reactors from this MBA. Division of MBAs into exclusive "process" and "storage" MBAs helps the operator design appropriate containment and surveillance measures to protect the nuclear materials in different forms distributed and/or stored in those areas. ${ }^{4,5}$ In the storage areas, all the materials can be in discrete containers, whereas in the process areas the materials are in buik forms in difficult-to-define containment. Movement of any material inio and out of these MBAs requires measurements and accounting.

MBA-2 of this facility has 4 transfer strata and 28 inventory strata for materials accounting. Most of the material transfers $(>99 \%)$ occur in three of the transfer strata. More than $97 \%$ of the inventory is in 8 of the 28 inventory strata. These 11 strata were selected for use in the computer simulations required to calculate the optimal allocation of LAEA resources for a verification procedure built around the $D$ statistic (see Sec. V). 


\section{Flow and Distribution of Materials}

The flow of materials through one of the process lines of this reference facility is illustrated in Fig. 4. The second process line also has identical unit operations. The feed streams of this plant are (1) MOX from a co-conversion facility with a $\mathrm{PuO}_{2}-$ to- $\mathrm{UO}_{2}$ ratio of $1: 1$ and (2) pure $\mathrm{UO}_{2}$ (with $\leq 0.72 \%{ }^{235} \mathrm{U}$ ) in a form ready for use as a diluent for the MOX. These materials are appropriately blended to obtain the fuel compositions of both the FBR and ATR lines. The FBR product line has a nominal plutonium content of $20 \%$ by weight of $\mathrm{PuO}_{2}$, and the ATR line has a nominal $\mathrm{PuO}_{2}$ content of $2.0 \%$. We assumed that the plant throughput for the FBP and ATR lines is $6.25 \mathrm{Mt}$ and $62.5 \mathrm{Mt}$ of MOX, respectively.

The facility has on hand about 2 Mt of 1:1 MOX as feed materiai (200 canisters) in MBA-1. The average inventory of MBA-3 is 100 FBR and 100 ATR fuel assemblies. This is equivalent to about $1620 \mathrm{~kg}$ of plutonium in MBA-3. The average inventory of plutonium-containing materials of various kinds in MBA-2 is the equivalent of $804 \mathrm{~kg}$ of plutonium. The distribution of MBA-2 inventory during normal operation of the plant is shown in Table $1^{6-8}$ The average value of the total inventory of plutonium at this facility is about 3.3 Mit as 1:1 MOX, finished fuel assemblies, and all forms of intermediates in the fuel preparation and fabrication areas. The maximum storage capacity of MBA-1 is $10 \mathrm{Mt}$ of 1:1 MOX powder (or 4.4 Mit of plutonium), and for MBA-3, the maximum storage capacity is 300 fuel assemblies (or $2.4 \mathrm{Mt}$ of plutonium equivalent). 


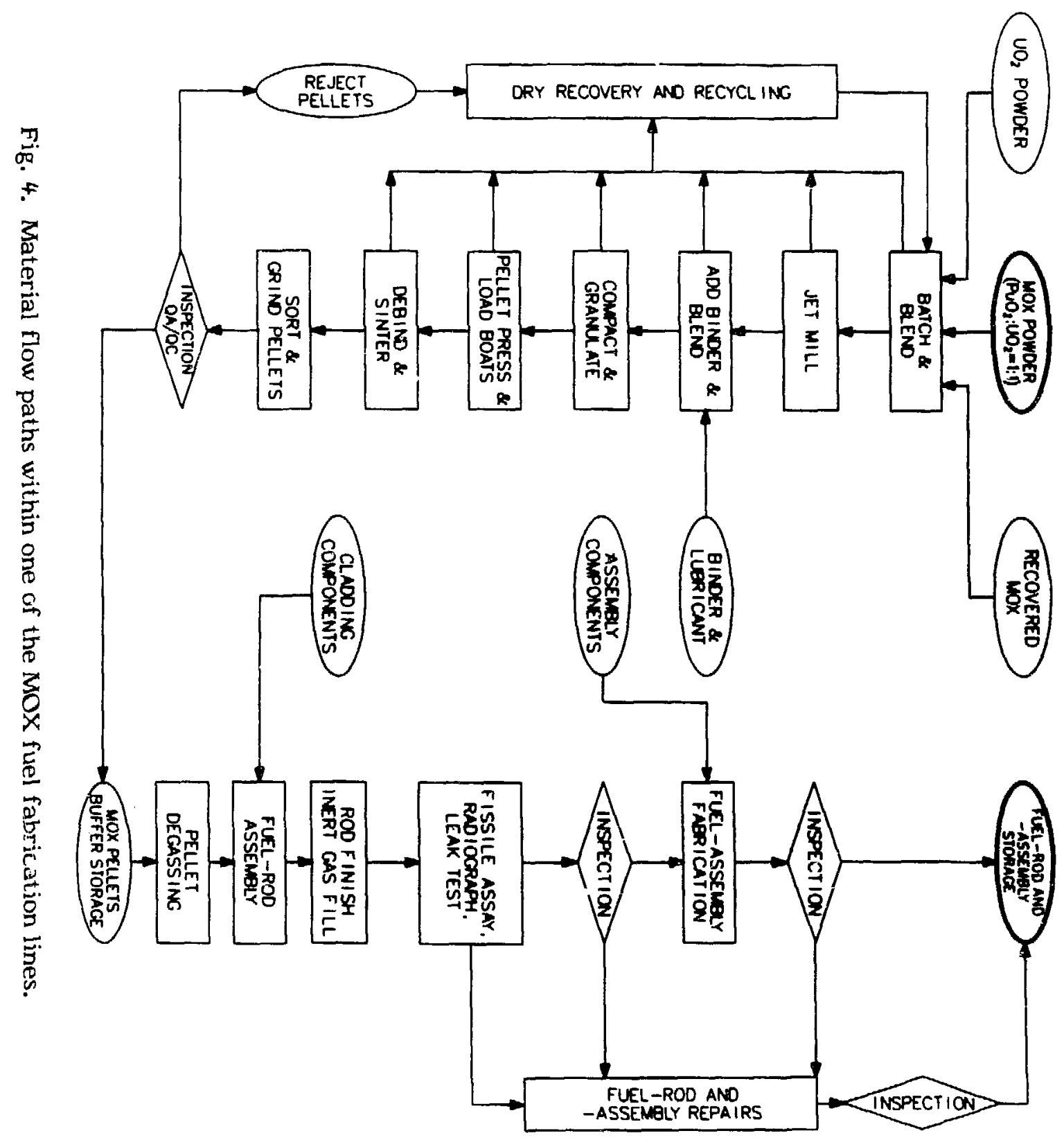


TABLE I

ASSUMED DISTRIBUTION OF PLUTONIUM AT THE PROCESSING AREAS OF THE MOX FACILITY DURING NORMAL OPERATIONS

\begin{tabular}{|c|c|c|c|c|}
\hline$\underline{\mathrm{MBA}}^{\mathrm{a}}$ & Description of Item & $\begin{array}{l}\text { No. of } \\
\text { iterns }\end{array}$ & $\begin{array}{l}\text { Pu/Item } \\
(\mathrm{kg}) \\
\end{array}$ & $\begin{array}{c}\text { Total Pu } \\
(\mathrm{kg}) \\
\end{array}$ \\
\hline $2-1$ & Blended MOX powder (cans) & 20 & 3.15 & 63.0 \\
\hline $2-1$ & $\begin{array}{l}\text { Recovered MOX of known Pu } \\
\text { content (cans) }\end{array}$ & 10 & 1.06 & 10.6 \\
\hline $2-1$ & FBR pellet stacks & 1500 & 0.0845 & 126.8 \\
\hline $2-1$ & FBR fuel pins & 3000 & 0.0845 & 253.5 \\
\hline $2-1$ & FBR fuel assemblies & 5 & 5.82 & 29.1 \\
\hline $2-1$ & Waste drums & 10 & 0.088 & 0.9 \\
\hline $2-1$ & Scrap (cans) & 5 & 1.102 & 5.5 \\
\hline $2-1$ & $\begin{array}{l}\text { 1:1 MOX powder feed (sealed } \\
\text { canisters) }\end{array}$ & 10 & 4.41 & 44.1 \\
\hline $2-2$ & Blended MOX powder (cans) & 20 & 0.882 & 17.6 \\
\hline $2-2$ & $\begin{array}{l}\text { Recovered MOX of known Pu } \\
\text { content (cans) }\end{array}$ & 5 & 1.06 & 5.3 \\
\hline $2-2$ & ATR pellet stacks & 1000 & 0.0353 & 35.3 \\
\hline $2-2$ & ATR fuel pins & 3000 & 0.0353 & 105.9 \\
\hline $2-2$ & ATR fuel assemblies & 5 & 10.36 & 51.8 \\
\hline $2-2$ & Waste drums & $3 C$ & 0.009 & 0.3 \\
\hline $2-2$ & Scrap (cans) & 5 & 0.661 & 3.3 \\
\hline $2-2$ & $\begin{array}{l}\text { l: } 1 \text { MOX powder feed (sealed } \\
\text { cans) }\end{array}$ & 10 & 4.41 & 44.1 \\
\hline $2-3$ & Waste drums from FBR line & 50 & 0.088 & 4.4 \\
\hline $2-3$ & Waste drums from ATR line & 100 & 0.009 & 0.9 \\
\hline $2-3$ & Liquid wastes (20 000 L) & - & - & 2.0 \\
\hline
\end{tabular}

Total Pu inventory $(\mathrm{kg}): \quad 804.4$

$\overline{\text { aSee Fig. } 3}$ for details. 


\section{DETECTION SENSITIVTY OF THE OPERATOR'S MATERLALS ACCOUNTING SYSTEM}

The assumptions necessary to calculate the detection sensitivity of the operator's materials accounting system are presented here along with the results of our sensitivity analyses. Details of material flows, materials inventory, and material measurements, which determine the detection sensitivity, are also given. The detection sensitivity is calculated only for the process MBA, that is, for MBA-2 (see Fig. 3), where the MOX is changed either chemically or physically. We specified that this facility operates 250 days/yr, which is about 21 days/calendar month ( 30 days). Hence, we calculated the 1-month setection sensitivities given below on the basis of transfers over a 21-day facility operation. Before presenting detection sensitivity results, we give the materials measured at each key measurement point (KMP).

\section{A. Key Measurement Points for MBA-2}

The KMPs associated with both transfers and inventories for this MBA, taken in order, are

FBR Line (MBA-2-1)

- KMP-1 input (1:1) MOX, $20.0 \mathrm{~kg}$ MOX/day in 8 cans. Measurements here include the mass/can (2.5 kg MOX) and the plutonium fraction $(0.441)$ by electrochemical analysis of samples. A portion of this input also serves the ATR line.

- KMP-A(1) recycle scrap, $6.25 \mathrm{~kg}$ MOX. The plutonium content $(\sim 1.1 \mathrm{~kg})$ is measured by NDA.

- KMP-A(2) recovered MOX from waste, $2.4 \mathrm{~kg}$ MOX. The plutonium content $(\sim 0.1 \mathrm{~kg})$ is measured by NDA.

- KMP-A(3) recoverable waste, $0.23 \mathrm{~kg}$ MOX. The plutonium content $(\sim 0.04 \mathrm{~kg})$ is measured by NDA.

- IKMP-A(4) laboratory samples, $0.05 \mathrm{~kg}$ MOX in 12 samples/day for the analytical laboratory. The plutonium fraction $(0.176)$ is determined by electrochemical analysis.

- KMP-A(5) holdup, $1.5 \mathrm{~kg}$ MOX with an estimated plutonium fraction of 0.176 . The variability of holdup is assumed as $50 \%$. 
- KMP-2 production fuel pellets, 52 stacks/day, or $\approx 25 \mathrm{~kg}$ MOX/day. The plutonium fraction $(0.176)$ is determined by electrochemical analysis.

- KMP-3 output of fuel assemblies, $\sim 16$ FBR assemblies per 21 days. The plutonium fraction is 0.176 and each assembly contairis $-5.82 \mathrm{~kg}$ of plutonium.

- KMP-A(6) 20 cans of blended MOX powder at $17.9 \mathrm{~kg} \mathrm{MOX/can,} \mathrm{or} 3.14$ $\mathrm{kg} \mathrm{Pu} / \mathrm{can}$.

- KMP-A(7) 10 cans of recovered MOX powder at $20.0 \mathrm{~kg} \mathrm{MOX/can,} \mathrm{or}$ $1.06 \mathrm{~kg} \mathrm{Pu} / \mathrm{can}$.

- KMP-B $1500 \mathrm{FBR}$ pellet stacks at $0.480 \mathrm{~kg} \mathrm{MOX} / \mathrm{stack}_{\text {f }}$ or $0.0845 \mathrm{~kg}$ Pu/stack.

- $\mathrm{KMP}-\mathrm{C} \quad 3000 \mathrm{FBR}$ pins at $0.480 \mathrm{~kg} \mathrm{MOX} / \mathrm{pin}$, or $0.0845 \mathrm{~kg} \mathrm{Pu} / \mathrm{pin}$.

- KMP-D 5 FBR assemblies at $33 \mathrm{~kg}$ MOX/assembly, or $5.82 \mathrm{~kg}$ Pu/assembly.

- KMP-E 10 drums of MOX-contaminated waste for recovery at $\sim 0.5 \mathrm{~kg}$ MOX/drum, or $0.089 \mathrm{~kg} \mathrm{Pu} /$ drum.

- KMP-A(8) 5 cans of MOX pellets for recycle at $6.35 \mathrm{~kg} \mathrm{MOX/can,} \mathrm{or}$ $1.1 \mathrm{~kg} \mathrm{Pu} / \mathrm{can}$.

ATR Line (MBA-2-2)

- KMP-A(1) recycle scrap, $\sim 9.64 \mathrm{~kg}$ MOX. The plutonium content $(0.17 \mathrm{~kg})$ is measured by NDA.

- KMP-A(2) recovered MOX from waste, $0.75 \mathrm{~kg}$ MOX. The plutonium content $(0.04 \mathrm{~kg})$ is determined by NDA.

- KMP-A(3) recoverable waste, $\sim 1.1 \mathrm{~kg}$ MOX. The plutonium content $(0.02 \mathrm{~kg})$ is measured by NDA.

- KMP-A(4) laboratory samples, $0.05 \mathrm{~kg}$ MOX in 30 samples/day for the analytical laboratory. The plutonium fraction $(0.0176)$ is determined by electrochemical analysis.

- KMP-A(5) holdup, $5.0 \mathrm{~kg}$ MOX with an estimated plutonium fraction of 0.0176 . The variability of the holdup is assumed as $50 \%$.

- KMP-4 production fuel pellets, 124 stacks/day, or $\sim 247.5 \mathrm{~kg}$ MOX/day. The plutonium fraction $(0.0176)$ is determined by electrochemical analysis. 
- KMP-5 output of fuel assemblies, $\sim 9$ ATR assemblies per 21 days. The plutonium fraction is 0.1763 and each assembly contains $\sim 10.36 \mathrm{~kg}$ of plutonium.

- KMP-A(6) 20 cans of blended MOX powder at $50.0 \mathrm{~kg}$ MOX/can, or $0.88 \mathrm{~kg} \mathrm{Pu} / \mathrm{can}$.

- KMP-A(7) 5 cans of recovered MOX powder at $20.08 \mathrm{~kg}$ MOX/can, or $1.06 \mathrm{~kg} \mathrm{Pu} / \mathrm{can}$.

- KMP-B 1000 ATR pilec stacks at $2.1 \mathrm{~kg}$ MOX/stack, or $0.0352 \mathrm{~kg}$ $\mathrm{Pu} /$ stack.

- KMP-C 3000 ATR pins at $2.0 \mathrm{~kg}$ MOX/pin, or $0.0352 \mathrm{~kg} \mathrm{Pu} / \mathrm{pin}$.

- KMP-D 5 ATR fuel assemblies at $587.4 \mathrm{~kg}$ MOX/assembly, or $10.36 \mathrm{~kg}$ Pu/assembly.

- KMP-E 30 drums of MOX-contaminated waste for recovery at $0.57 \mathrm{~kg}$ MOX/drum, or $0.01 \mathrm{~kg} \mathrm{Pu} /$ drum.

- KMP-A(8) 5 cans of MOX pellets for recycle at $37.5 \mathrm{~kg}$ MOX/can, or $0.66 \mathrm{~kg} \mathrm{Pu} / \mathrm{can}$.

\section{Waste Recovery (MBA-2-3)}

- KMP-6 output to waste disposal, $0.056 \mathrm{~kg} \mathrm{FBR} \mathrm{MOX/day} \mathrm{and} 0.56 \mathrm{~kg}$ ATR MOX/day. The plutonium content $(0.02 \mathrm{~kg})$ is determined by NDA.

- KMP-A(1) holdup, $0.17 \mathrm{~kg}$ MOX with an estimated plutonium fraction of 0.06. The variability of the holdup is assumed as $50 \%$.

- KMP-E(1) 50 drums of MOX-contaminated waste from FBR line at $0.5 \mathrm{~kg}$ MOX/drum, or $0.089 \mathrm{~kg} \mathrm{Pu} /$ drum.

- KMP-E(2) 100 drums of MOX-contaminated waste from ATR line at $0.57 \mathrm{~kg} \mathrm{MOX} /$ drum, or $0.01 \mathrm{~kg} \mathrm{Pu} /$ drum.

- KMP-F liquid wastes in critically safe storage tanks containing $2 \mathrm{~kg}$ of plutonium in a volume of $20000 \mathrm{~L}$.

Each of these KMPs is used by the operator in his materials balance equation for MBA-2. Additional information needed to calculate the materials balance variance is the measurement errors associated with each of the KMPs. These are given in Tables II and III. ${ }^{9-11}$ 
TABLE II

\section{OPERATOR'S MEASUREMENT STANDARD DEVIATIONS FOR DETERMINATION OF PLUTONIUM CONCENTRATION ${ }^{a}$}

Measurement Type

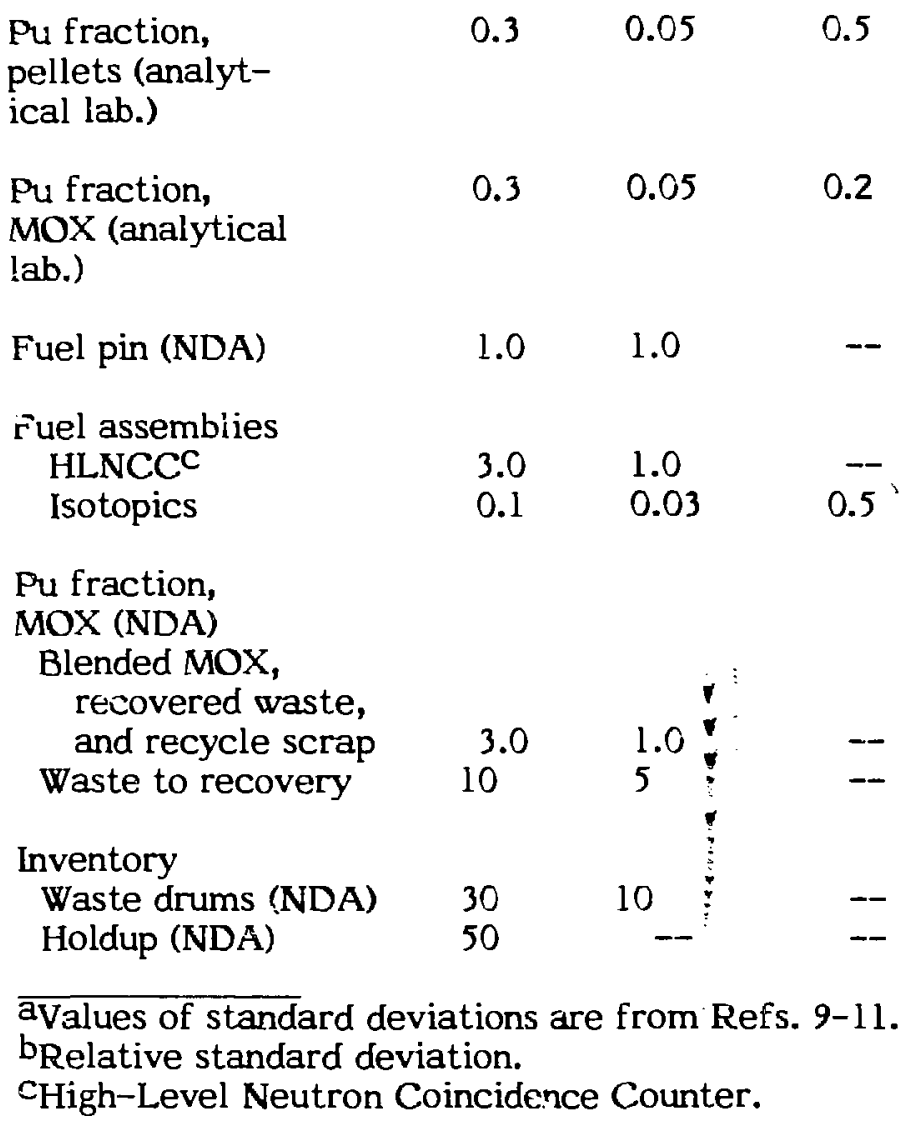

\section{B. Detection Probability for MBA-2 (Abrupt Diversion)}

To obtain the detection probability of the materials accounting system for MBA-2, we derive the variance equation for MBA-2 from the materials balance equation. Then, substituting the mass transfers/inventories for each KMP given above and the instrument measurement standard deviations, we can calculate the total variance.

The materials balance equation can be written so that the operator closes his balance at the production pellet stacks or the output fuel assemblies. We calculate the variance for each case. Results for the case where th orerator closes the 
TABLE III

OPERATOR'S MASS MEASUREMENT STANDARD DEVIATIONS ${ }^{a}$

\begin{tabular}{|c|c|c|}
\hline Mass & \multicolumn{2}{|c|}{ Instrument $\mathrm{SDs}(\mathrm{kg})$} \\
\hline Measurement & Rand. & Correl. \\
\hline MOX cans & 0.0002 & 0.0004 \\
\hline $\begin{array}{l}\text { FBR, ATR } \\
\text { pellet stacks }\end{array}$ & 0.0004 & 0.0006 \\
\hline Lab. samples & 0.0001 & 0.0002 \\
\hline
\end{tabular}

materials balance at the production pellet stacks are discussed in detail below (also see Appendix B). Subsequently, the results for the case where the operator closes his materials balance at the fuel assemblies are presented. In addition, we present results for a 6-month and a 12-menth accounting period, when cleanout and pliysical inventory take place.

The variance contributions at the individual KMPs and their total are given in Table IV for the case where the operator closes his materials balance at the production pellet stacks. The throughput of this facility over a 2l-day accounting period is $21 \times 10 \mathrm{~kg} \mathrm{PuO} 2 /$ daj $\times 0.882=185.2 \mathrm{~kg}$ of plutonium. Hence, the value $\sigma_{\mathrm{MBA}-2}=$ $1.466 \mathrm{~kg}$ of plutonium represents $-0.8 \%$ of plutonium throughput. One can also determine the ratio of $\sigma_{\mathrm{MBA}-2}$ to the plutonium inventory. The inventory in interim storage is $-804 \mathrm{~kg}$ of plutonium, so $\mathrm{c}_{\mathrm{MBA}-2}=1.466 \mathrm{~kg}$ of plutonium represents $-0.2 \%$ of inventory.

An examination of Table IV reveals that only a few inventory items are major contributors to the total variance. These are the cans of FBR MOX powder, KMP-A(6), contributing $\sim 0.36 \mathrm{~kg}^{2}$; the FBR fuel assemblies, KMP-D, contributing $-0.31 \mathrm{~kg}^{2}$; and the ATR fuel assemblies, KMP-D, contributing $-0.97 \mathrm{~kg}^{2}$. These contributions add up to $\sim 1.64 \mathrm{~kg}^{2}$ of plutonium, which is $-76 \%$ of the total variance. Because the sensitivity of an accounting system to materials loss increases as the variance of that accounting system decreases, one should probably examine the possibility of reducing the inventory of these items to the lowest practicable level at the time of closing the materials balance. 
TABLE IV

VARIANCE CONTRIBUTIONS AT KEY MEASUREMENT POINTS FOR A 21-DAY ACCOUNTING PERIOD

KMP

1

FBR Line
$A(1)$
$A(2)$
$A(3)$
$A(4)$
$A(5)$
2
$A(6)$
$A(7)$
$B$
$C$
$D$
$E$
$A(8)$

$A(8)$
Material

Input MOX (FBR and ATR)
Variance

$\left(\mathrm{kg}^{2} \mathrm{Pu}\right)$

0.1539

ATR Line

A(1)

$A(2)$

$A(3)$

$A(4)$

$A(5)$

4

$A(6)$

$A(7)$

B

C.

D

E

$A(8)$
Recycle scrap

Rccovered waste

Waste to recovery

L.aboratory samples

Holdup

Output FBR pellet stacks

Cans of MOX powder

MOX from waste recovery

FBR pellet stacks

FBR pins

FBR assemblies

Waste to recovery

Pellets for recycle
0.0022

0.0001

0.0001

0.0001

0.0351

0.0273

0.3557

0.0202

0.0193

0.0043

0.3051

0.0145

0.0112

Recycle scrap

Recovered waste

0.0002

Waste to recovery

0.0001

Laboratory samples

0.0001

Holdup

0.0001

Output ATR pellet stacks

0.0039

Cans of MO powder

0.0237

MOX from waste recovery

0.0101

ATR pellet stacks

0.0022

ATR pins

0.0007

ATR assemblies

0.9654

Waste to recovery

0.0005

Pellets for recycle

0.0039

Waste Recovery

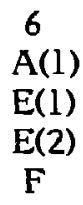

Output to waste disposal

0.0072

Holdup

0.0001

Waste from FBR line

$0.072 \%$

Waste from ATR line

0.0018

Liquid waste

$\underline{0.0800}$

Total:

2.1492

$\sigma_{\mathrm{MBA}-2}=1.466 \mathrm{~kg}$ of plutonium 
Current materials accounting practices at fuel fabrication facilities would justify the deletion of six variance terms from Table IV to arrive at a lower total variance for $M B A-2$. These six variance terms correspond to inventories from $\mathrm{KMP}-\mathrm{B},-\mathrm{C}$, and $-\mathrm{D}$ of the $\mathrm{ATR}$ and FBR lines. The reason given for deleting these inventory terms is the ongoing practice of assuming that the fuel-pellet stacks, fuel pins, and fuel assemblies are collections of items from previously measured product pellets and stored as items in secure storage locations. Ignoring these inventory items has the obvious advantage of reducing the total variance for MBA-2 to $\sim 0.8 \mathrm{~kg}^{2}$ of plutonium, which gives a $\sigma_{\mathrm{MBA}-2}$ of $-0.9 \mathrm{~kg}$ of Pu.

However, these pellet stacks, fuel pins, and fuel assemblies are located in MBA-2, and the materials balance equation should reflect that fact. Furthermore, if these items are simply ignored at monthly accounting times, the operator cannot accertain whether substitution or tampering has occurred during the interval. NDA measurements of this material provide some degree of protection against substitution or tampering and, at the same time, make it possible to write a complete materials balance equation for MBA-2. The result is a larger, but moie realistic, variance for MBA-2, as shown in Table IV.

In Table $V$ are given values of the calculated parameter $\sigma$ for $M B A-2$, this $\sigma$ expressed as a percentage of the plutonium throughput, and the detection probability for 1-, 6-, and 12-month accounting periods for the two cases where the operator closes his materials balance at the production pellet stacks and at the output fuel assemblies. The values of $\sigma$ for the 6 - and 12 -month accounting periods were determined assuming that all measurement instruments are recalibrated monthly. The comparatively larger values of $\sigma$ obtained for materials balance closure at the output fuel assemblies come about because we assumed that the plutoniuri content of the fuel assemblies is measured by NDA instruments rather than by weight and chemical assay of the pellets; the latter method is subject to much smaller measurement error standard deviation than are NDA methods.

We calculated the detection probabilities assuming an abrupt diversion of $8 \mathrm{~kg}$ of plutonium and an alarm level of $1.96 \mathrm{\sigma}$. With this alarm level, the (two-sided) false-alarm probability is $5 \%$. The false-alarm probability can be decreased by increasing the alarm level; however, detection probabilities will also decrease (for the same $8 \mathrm{~kg}$ of plutonium). In all but two cases, the alarm levels, $1.96 \sigma$, are considerably less than $8 \mathrm{~kg}$, and the corresponding detection probabilities are approximately $94 \%$ or greater (column three, Table V, and the first case of column four). 


\section{TABLE V}

\section{DETECTION PROBABILITIES FOR MBA-2 FOR A DETECTION \\ SENSITIVITY OF $8 \mathrm{~kg}$ OF PLUTONIUM \\ (Alarm level $=1.96 \sigma$, false-alarm probaiility $=5 \%$ )}

Accounting

Time

(months)

1

6

12
Calculated

Parameters

$\sigma(\mathrm{kg})$

$\sigma(\%$ of throughput)

$\mathrm{DPb}(\%)$

$\sigma(\mathrm{kg})$

$\sigma(\%$ of throughput)

DP $(\%)$

$$
\begin{gathered}
\sigma \text { (kg) } \\
\sigma(\% \text { of throughput) } \\
\text { DP (\%) }
\end{gathered}
$$

\begin{tabular}{|c|c|}
\hline Operator's $\mathrm{MB}^{\mathrm{a}}$ & Closed at \\
\hline Production & Output Fuel \\
\hline Pellet Stacks & Assemblies \\
\hline 1.4660 & 2.2792 \\
\hline$\sim 0.8$ & $\sim 1.2$ \\
\hline 99.9 & 93.9 \\
\hline 1.7807 & 4.6309 \\
\hline$\sim 0.2$ & $\sim 0.4$ \\
\hline 99.4 & $43.3^{C}$ \\
\hline 2.1079 & 6.4025 \\
\hline$\sim 0.1$ & $\sim 0.3$ \\
\hline 96.6 & $23.8 \mathrm{C}$ \\
\hline
\end{tabular}

$\overline{\mathrm{a} \overline{\mathrm{B}} \text { - materials }}$ balance.

bDP - detection probability.

CFor this detection probabilit , $t^{\prime}$ alarm level, $1.96 \sigma$, is greater than $8 \mathrm{~kg}$ of plutonium.

In the two cases where the operator closes his materials balance at the output fuel zssemblies at 6- and 12-month intervals, detection probabilities for an abrupt loss of $8 \mathrm{~kg}$ of plutonium are approximately $43 \%$ and $24 \%$, respectively. These comparatively small detection probabilities are the direct result of the large values of $\sigma$ $(\sim 4.6$ and $\sim 6.4 \mathrm{~kg})$ for these two cases. In each case, the alarm level, $1.96 \sigma$, is greater than $8 \mathrm{~kg}$ of plutonium.

\section{Detection Probability for MBA-2 (Protracted Diversion)}

The goal of this section is to quantify the sensitivity of the accounting system to protracted losses of material based on unfalsified operator data only. Much recent safeguards literature concerns the subject of recurring-loss detection, and standard procedures can be easily applied to simulated data. Appendix $\mathrm{C}$ contains a detailed treatment of this subject together with a short reference list. A nonmathematical discussion is included here to serve as an introduction.

The principles of protracted-loss detection are straightforward. After each materials balance is obtained, an evaluation is made of all materials balances observed to that time. Basically, that evaluation concerns how consistent the 
balance sequence is with the zero-loss hypothesis; if the degree of inconsistency is too great, an alarm is generated. By analyzing materials balances in near real time, the potential exists to detect recurring losses promptly--before those losses have accumulated to an appreciable quantity.

As an example, one prospective sequential procedure follows along the lines of repeated significance testing. The cumulative MUF (CUMUF) since the start of the monitoring period could be calculated at the end of each month and compared with the threshold based on a nominal 5\% significance test for that CUMUF. In this way accountability data over longer times are used to test for long-term material loss.

The CUMUF approach as above is simple and has a natural appeal. Unfortunately, it also has several drawbacks. Among them is its inordinately high falsealarm rate. Sequentially performing 12 CUMUF tests in a year, where each individual test has a $5 \%$ false-alarm rate, means that the chance of at least one false alarm occurring during the set of 12 tests is much larger than $5 \%$. Secondly, the CUMUF is relatively insensitive to many loss scenarios because it is essentially equivalent to a long-term average of MUFs. As a case in point, if a protracted loss began in the 8 th month of a 12-month monitoring period, the CUMUF approach would not give a timely response. This lack of sensitivity is caused by the averaging of many MUFs from no-loss months with a few MUFs corresponding to losses, so that the long-term average is dominated by measurement noise from no-loss months.

These and other considerations have motivated work in recent years on sequential tests (see the reference list in Appendix C). Many test procedures have been examined; a prominent one serves as an example to illustrate sensitivity to protracted loss in MBA-2.

Using information described previously regarding error propagation, we simulate sequences of 12 monthly materials balances. Corresponding to each sequence is its loss scenario, which specifies the amount of loss (if any) in each month. An observed balance sequence can be thought of as being produced by superimposing correlated measurement errors on the underlying loss scenario. There are, in principle, an infinite number of loss scenarios that could hypothetically occur. For what follows, we consider scenarios for which an $8-\mathrm{kg}$ loss is evenly spread over $\mathrm{n}(\mathrm{n}=1,2$, $4,6,8,12$ ) monthly inventory periods.

Materials balances here are inventory-dominated. In other words, the impacts of uncertainties in the estimated inventories are much larger than the impacts of uncertainties in the estimated transfers. This factor, coupled with the relatively small systematic uncertainties, implies that the covariance structure for the materials balance sequence resembles that of a first-order moving average process of 
conventional time series. Using available information concerning measurement uncertainties, we calculate that the variance of each monthly materials balance is $2.15 \mathrm{~kg}^{2}=(1.47 \mathrm{~kg})^{2}$. The covariance tetween successive materials balances is -0.97 $\mathrm{kg}^{2}$, and the covariance between nonsuccessive materials balances is zero owing to monthly instrument recalibrations.

Given the covariance :tructure, the sequence of materials balances is converted to the sequence of innovations (in the international literature, the terms "ITMUF sequence" and "sequence of MUF residuals" are sometimes used). The innovations are amenable to standard procedures of sequential analysis. One such procedure is a CUSUM technique known as Page's test, which is detailed in Appendix C. This test was applied to simulated materials balances from the MDX-line process.

Thresholds for the sequential testing procedure were chosen to provide an overall $5 \%$ false-alarm rate. That is, the probability of a false alarm at any time during the 12 -month monitoring period is $5 \%$. This rate is arbitrary but conforms to the "limit-of-error tradition" for evaluating safeguards data. In addition, thresholds for a $1 \%$ false-alarm rate were used. Alternatively, it is also possible to select thresholds to provide a specified detection probability for a given loss scenario.

As summarized in Table VI, a protracted loss of $8 \mathrm{~kg}$ is detectable no matter how the loss is spread over the inventory periods. For the $5 \%$ false-alarm rate, detection probabilities exceeded $98 \%$ for all of the loss scenarios considered. For the $1 \%$ false-alarm rate, the probabilities exceed $95 \%$. As a general rule, the sensitivity to detect an $8-\mathrm{kg}$ loss declines slightly as the loss is spread over more inventory periods.

Note: sensitivity is strongly affected by monthly instrument recalibration. If no recalibration occurred, a sequence of MUFs where each MUF showed an apparent loss would be consistent with two explanations: (1) the presence of so-called systematic measurement errors transcending several inventory periods, and (2) protracted loss of material. Maintaining low false-alarm rates requires that the sequential test frequently give the benefit of the doubt to explanation (1) when explanation (2) is correct, thereby reducing sensitivity. Under monthly recalibration, a long series of MUFs showing apparent losses is not reasonably attributable to explanation (1) and an alarm occurs. To illustrate the gain of sensitivity owing to monthly recalibration, consider the scenario where a protracted loss of $0.67 \mathrm{~kg}$ occurs for each of the 12 months. As noted in Table VI, the sequential procedure with a $5 \%$ false-alarm rate detects this loss with a $98 \%$ probability. If there were no recalibrations during the year, the loss would be detected with only a $33 \%$ probability. 
TABLE VI

DETECTION PROBABILITIES FOR VARIOUS LOSS SCENARIOS ${ }^{a}$

Month in Which Loss Occurred

\begin{tabular}{|c|c|c|c|c|c|c|c|c|c|c|c|c|c|c|c|}
\hline \multicolumn{12}{|c|}{ Month in Which Loss Occurred } & \multirow{2}{*}{\multicolumn{2}{|c|}{$\begin{array}{l}\text { Detection } \\
\text { Probability } \\
(\%) \\
\end{array}$}} & \multirow{2}{*}{\multicolumn{2}{|c|}{$\begin{array}{c}\text { Lag }_{c} \\
\text { Time } \\
\text { (months) }\end{array}$}} \\
\hline 1 & 2 & 3 & 4 & 5 & $\frac{6}{\text { ount of }}$ & $\frac{7}{0.055}(k$ & 8 & 9 & $\underline{10}$ & 11 & $\underline{12}$ & & & & \\
\hline 0.67 & 0.67 & 0.67 & 0.67 & 0.67 & 0.67 & 0.67 & 0.67 & 0.67 & 0.67 & 0.67 & 0.67 & 98 & 95 & 5.2 & 6.5 \\
\hline 1.00 & 1.00 & 1.00 & 1.00 & 1.00 & 1.00 & 1.00 & 1.00 & 0.00 & 0.00 & 0.00 & 0.00 & 99 & 99 & 3.6 & 4.5 \\
\hline 0.00 & 0.00 & 1.00 & 1.00 & 1.00 & 1.00 & 1.00 & 1.00 & 1.00 & 1.00 & 0.00 & 0.00 & 99 & 99 & 3.1 & 4.0 \\
\hline 0.00 & 0.00 & 0.00 & 0.00 & 1.00 & 1.00 & 1.00 & 1.00 & 1.00 & 1.00 & 1.00 & 1.00 & 99 & 98 & 3.0 & 3.9 \\
\hline 1.33 & 1.33 & 1.33 & 1.33 & 1.33 & 1.33 & 0.00 & 0.00 & 0.00 & 0.00 & 0.00 & 0.00 & 99 & 99 & 2.7 & 3.5 \\
\hline 0.00 & 0.00 & 0.00 & 1.33 & 1.33 & 1.33 & 1.33 & 1.33 & 1.33 & 0.00 & 0.00 & 0.00 & 99 & 99 & 2.2 & 3.5 \\
\hline 0.00 & 0.00 & 0.00 & 0.00 & 0.00 & 0.00 & 1.33 & 1.33 & 1.33 & 1.33 & 1.33 & 1.33 & 99 & 99 & 2.2 & 3.0 \\
\hline 2.00 & 2.00 & 2.00 & 2.00 & 0.00 & 0.00 & 0.00 & 0.00 & 0.00 & 0.00 & 0.00 & 0.00 & 99 & 99 & 1.9 & 2.4 \\
\hline 0.00 & 0.00 & 0.00 & 0.00 & 2.00 & 2.00 & 2.00 & 2.00 & 0.00 & 0.00 & 0.00 & 0.00 & 99 & 99 & 1.4 & 1.9 \\
\hline 0.00 & 0.00 & 0.00 & 0.00 & 0.00 & 0.00 & 0.05 & 0.00 & 2.00 & 2.00 & 2.00 & 2.00 & 99 & 99 & 1.4 & 1.9 \\
\hline 4.00 & 4.00 & 0.00 & 0.00 & 0.00 & 0.00 & 0.00 & 0.00 & 0.00 & 0.00 & 0.00 & 0.00 & 99 & 99 & 0.9 & 1.1 \\
\hline 0.00 & 0.00 & 0.00 & 0.00 & 0.00 & 4.00 & 4.00 & 0.00 & 0.00 & 0.00 & 0.00 & 0.00 & 99 & 99 & 0.6 & 0.9 \\
\hline 0.00 & 0.00 & 0.00 & 0.00 & 0.00 & 0.00 & 0.00 & 0.00 & 0.00 & 0.00 & 4.00 & 4.00 & 99 & 99 & 0.6 & 0.8 \\
\hline 8.00 & 0.00 & 0.00 & 0.00 & 0.00 & 0.00 & 0.00 & 0.00 & 0.00 & 0.00 & 0.00 & 0.00 & 99 & 99 & 0.1 & 0.4 \\
\hline 0.00 & 0.00 & 0.00 & 0.00 & 0.00 & 0.00 & 8.00 & 0.00 & 0.00 & 0.00 & 0.00 & 0.00 & 99 & 99 & 0.0 & 0.1 \\
\hline 0.00 & 0.00 & 0.00 & 0.00 & 0.00 & 0.00 & 0.00 & 0.00 & 0.00 & 0.00 & 0.00 & 8.00 & 99 & 99 & 0.0 & 0.0 \\
\hline
\end{tabular}

Based on 10000 simulated sequences per loss scenario, so that empirical probabilities have a standard deviation of roughly $0.5 \%$.

b Threshold values for Page's test are $(h, k)=(3.3,0.5)$ for the $5 \%$ false-alarm rate and $(h, k)=(4.6,0.5)$ for the $1 \%$ false-alarm rate; once a false alarm occurs, the test is restarted.

"'Lag time" denotes he average number of months from observation of the first materials balance for which a loss occurred until an siarm is generated. Nondetections are ignored in this calculation. 


\section{IAEA INSPECTOR VERIFICATION ACTIVITIES}

The MOX bulk-handling facility is a real challenge to inspector verification because of the variety of physical forms of material and compositions. ${ }^{12-14}$ Table VII summarizes possible verification methods, ${ }^{15-20}$ which include measurement and containment/surveillance. A variety of alternative measurement techniques, other than those listed here, may be satisfactorily used to achieve the same objectives. $13,21-24$

The results from Sec. III quantified the performance of the accounting system based on the operator's reported data. However, IAEA inspection should consider potential falsification of operator's reported data to conceal diversion of materials. To counter possible falsification, an inspector independently remeasures selected items and compares his values with those reported by the operator. If observed discrepancies are within reasonable limits based on the measurement uncertainties involved, there is no evidence of data falsification.

Inspector verification is pursued by one of the two generic procedures, namely, the (MUF-D) statistic and attributes/variables sampling. The first procedure is described in Sec. V. The second procedure, which is discussed in this section, is useful when an inspector has two instruments available--one with low measurement uncertainties but which is expensive (in time and/or money) to operate, and another with larger uncertainties but which costs less. A single NDA instrument with long and short counting times can serve the same purpose.

The attributes instrument, which has low capital and operating costs, is used to measure many items and is capable of detecting gross discrepancies. The variables instrument, which has low measurement uncertainties, is used to measure a few items and is capable of detecting minor discrepancies. Used in combination, the two instrumental measurements protect against two basic means of $f$ lsifying a goal quantity of material, that is, falsifying a small number of items by large amounts and falsifying a larger number of items by small amounts.

Comparisons are made item by item. A relatively large number of items are measured by the attributes instrument. Items for which the observed difference between the attributes value and the reported value exceeds a threshold, such as a 2- $\sigma$ limit, are remeasured using the variables instrument. The remeasurement is intended to resolve any attributes false alarms or to confirm actual discrepancies. In addition, a second, smaller sample of items is also measured by the variables instrument. If any of the differences between the variables value and the reported value exceeds a threshold, an alarm is generated. 
KEY MEASUREMENT POINTS AND VERIFICATION ACTIVITIES

\begin{tabular}{|c|c|c|}
\hline KMP & Material Characteristics & Measurement or $\mathrm{C} / \mathrm{S}^{\mathrm{a}}$ Activities \\
\hline 1 & Receipt of 1:1 MOX & $\begin{array}{l}\text { Verify seals, attributes } \\
\text { sampling, check surveillance } \\
\text { records (if any) }\end{array}$ \\
\hline $2-5$ & $\begin{array}{l}\text { Shipment of fuel pins and } \\
\text { assemblies }\end{array}$ & $\begin{array}{l}\text { Verify seals, HLNCCb measure- } \\
\text { ments and apply seals, check } \\
\text { surveillance records (if any) }\end{array}$ \\
\hline 6 & Transfer of solid wastes & NDA using drum counter ${ }^{c}$ \\
\hline A & $\begin{array}{l}\text { Sealed cans of 1:1 MOX } \\
\text { (verified) }\end{array}$ & Verify and replace seals \\
\hline A & $\begin{array}{l}\text { Sealed cans of } 1: 1 \text { MOX } \\
\text { (stored at shipper's value) }\end{array}$ & Verify andi replace seals \\
\hline B & Unsealed cars of 1:1 MOX & $\begin{array}{l}\text { Weigh, NDA, sample for labora- } \\
\text { tory analysis, and apply seals } \\
\text { as necessary }\end{array}$ \\
\hline B & Recovered MOX & $\begin{array}{l}\text { Weigh, NDA, sample for labora- } \\
\text { tory analysis, and apply seals } \\
\text { as necessary }\end{array}$ \\
\hline B & $\begin{array}{l}\text { MOX powder cans } \\
\text { (FBR and ATR lines) }\end{array}$ & $\begin{array}{l}\text { Weigh, NDA, sample for labora- } \\
\text { tory analysis, and apply seals } \\
\text { as necessary }\end{array}$ \\
\hline B & $\begin{array}{l}\text { Clean scrap cans } \\
\text { (FBR and ATR lines) }\end{array}$ & $\begin{array}{l}\text { Weigh, NDA, sample for labora- } \\
\text { tory analysis, and apply seals } \\
\text { as necessary }\end{array}$ \\
\hline $\mathrm{C}$ & $\begin{array}{l}\text { Fuel assemblies } \\
\text { (FBR and ATR types) }\end{array}$ & $\begin{array}{l}\text { HLNCC counting, verify, and } \\
\text { apply or replace seals } \\
\text { as necessary }\end{array}$ \\
\hline $\mathrm{D}$ & $\begin{array}{l}\text { Fuel pins } \\
\text { (FBR and ATR types) }\end{array}$ & $\begin{array}{l}\text { NDA using PMCA }{ }^{d} \text { and } G e(L i) \\
\text { detector }\end{array}$ \\
\hline $\mathbf{E}$ & $\begin{array}{l}\text { Fuel pellet stacks } \\
\text { (FBR and ATR types) }\end{array}$ & NDA using FPTCe or BCNCf \\
\hline $\mathrm{F}$ & $\begin{array}{l}\text { Waste drums } \\
\text { (from FBR and ATR lines) }\end{array}$ & NDA using drum counter \\
\hline G & Liquid wastes (all types) & Sample for assay \\
\hline \multicolumn{3}{|c|}{$\begin{array}{l}\text { aC/S - Containment/surveillance } \\
\text { bHLNCC - High-Level Neutron Coincidence Counter. } \\
\text { CDrum counter - Segmented gamma scan or equivalent. } \\
\text { dPMCA - Fortable Mini Multichannel Analyzer. } \\
\text { eFPTC - FBR Pin Tray Counter. } \\
\text { f }_{\text {BCNC - Birdcage Neutron Coincidence Counter. }}\end{array}$} \\
\hline
\end{tabular}




\section{A. Storage Vaults-Verification by Attributes Sampling}

There are two storage vaults in our reference facility. The first, MBA-1, contains canisters of 1:1 MOX powder. The second, MBA-3, contains both FBR and ATR fuel assemblies. Standard methods ${ }^{25}$ are available for calculating the number of items or batches (sample size) that need to be drawn from each of these strata such that, with a desired probability, a falsified item will be included in the sample (attributes sampling). In Table VIII, we give the normal storage capacities for the different items, the plutonium content for each item, and the attributes sample sizes required for verification at $95 \%$ and $75 \%$ detection probabilities.

Sample sizes in Table VIII are stratum-specific. That is, these sizes provide the required confidence against an 8-kg loss in the given stratum. An alternate approach would be to consider an 8 -kg loss over all strata combined, but sample sizes would have to be somewhat larger.

\section{B. Transfers and Inventories for MBA-2-Verification by Attributes/Variables Sampling}

An option available to the IAEA inspector is verifying the different transfer and inventory strata of MBA-2 by the attributes/variables sampling methods discussed in detail in Ref. 26. Using a specified goal quantity ( $8 \mathrm{~kg}$ of plutonium in this case) and the assumption of uniform falsification of falsified items, we can calculate attributes and variables sample sizes for each stratum and for a required detection probability if we know the measurement standard deviations of the operator's and inspector's instruments.

TABLE VIII

ATTRIBUTES SAMPLE SIZES FOR 95\% AND 75\% DETECTION PROBABILITIES FOR ITEMS IN STORAGE VAULTS

\begin{tabular}{|c|c|c|c|c|}
\hline$\underline{\mathrm{MBA}}$ & $\begin{array}{c}\text { Normal } \\
\text { Capacity }\end{array}$ & $\begin{array}{c}\text { Pu/Item } \\
(\mathrm{kg})\end{array}$ & $\begin{array}{c}95 \% \\
\text { Sample Size }\end{array}$ & $\begin{array}{c}75 \% \\
\text { Sample Size }\end{array}$ \\
\hline 1 & 200 canisters & 4.41 & 153 & 100 \\
\hline 3 & 100 FBR assemblies & 5.82 & 78 & 50 \\
\hline 3 & 100 ATR assemblies & 10.36 & 95 & 75 \\
\hline
\end{tabular}


During an accounting period for the MOX facility, only about half the total number of strata contain $8 \mathrm{~kg}$ of plutonium or more, so it is only from those strata that a divertor can obtain a goal quantity of plutonium. Inspector verification of the operator's transfer measurements for MBA-2 can be made on the input cans of MOX and the FBR and ATR pellet stacks or, alternatively, on the input cans of MOX and the FBR and ATR fuel assemblies (these are the only transfer strata that contain $8 \mathrm{~kg}$ of plutonium or more during an accounting period). We give attributes and variables sample sizes for both the pellet stacks and the fuel assemblies. We also give results for those inventory strata that contain a goal quantity $(8 \mathrm{~kg}$ ) of plutonium or more. The remaining strata of MBA-2 (those containing less than a goal quantity of plutonium) can be verified by measuring a single item from each stratum at the variables level.

Table IX shows the attributes and variables sample sizes for $95 \%$ and $75 \%$ detection probabilities for those MBA-2 strata that satisfy the requirements discussed above. To obtain these results, we assumed that the inspector's measurement standard deviations were 50\% greater than the operator's measurement standard deviations. As in Table VIII, sample sizes are stratum-specific; that is, they provide the required confidence against an $8-\mathrm{kg}$ loss in each stratum. Both attributes and variables sample sizes are computed by simulation, as discussed in Ref. 26.

The cans of MOX are measured at the attributes level by NDA methods (neutron counting and high-resolution $\gamma$-counting). NDA is also used at the variables level for this MOX, but the method was coincidence counting. The FBR and ATR pellet stacks are measured at the attributes level using a portable NDA $\gamma$-counter and at the variables level using electrochemical analysis (sampling and destructive analysis). Should the inspector wish to verify the output FBR and ATR fuel assemblies, he can use a portable $\gamma$-counter at the attributes level and HLNCC-based NDA measurements at the variables level.

Sample sizes (relative to corresponding numbers of items in the strata) for a specified detection probability depend not only on the measurement standard deviations but also on the plutonium content of each item. The plutonium content of the MOX cans (and fuel assemblies) is much larger than the plutonium content of either the FBR or ATR pellet stacks. Hence, the relative sample size for the MOX cans (and fuel assemblies) is much greater than for the pellet stacks for the same detection probability. 
TABLE IX

ATTRIBUTES AND VARIABLES SAMPLE SIZES

FOR $95 \%$ AND $75 \%$ DETECTION PROBABILITIES

FOR MBA-2 STRATA CONTAINING $8 \mathrm{~kg}$ OF PLUTONIUM OR MORE

Sample Sizes

\begin{tabular}{|c|c|c|c|c|c|}
\hline No. of & Pu/Item & $95 \%$ Detectio & Probability & $75 \%$ Detectio & Probability \\
\hline Items & (kg) & Attributes & Variables & Attributes & Variables \\
\hline 168 cans of MOX & 1.10 & 50 & 3 & 25 & 1 \\
\hline $\begin{array}{l}1092 \text { FBR pellet } \\
\text { stacks }\end{array}$ & 0.0845 & 30 & 2 & 14 & 1 \\
\hline $\begin{array}{l}\text { 2604 ATR pellet } \\
\text { stacks }\end{array}$ & 0.0352 & 30 & 2 & 14 & 1 \\
\hline $\begin{array}{l}16 \mathrm{FBR} \\
\text { assemblies }\end{array}$ & 5.82 & 11 & 9 & 8 & 3 \\
\hline 9 ATR assemblies & 10.36 & 8 & $6^{a}$ & 7 & 4 \\
\hline 20 cans FBR MOX & 3.14 & 11 & 2 & 7 & 1 \\
\hline 10 cans FBR MOX & 1.06 & 2 & 1 & 1 & 1 \\
\hline $\begin{array}{l}1500 \mathrm{FBR} \text { pellet } \\
\text { stacks }\end{array}$ & 0.0845 & 43 & 1 & 20 & 1 \\
\hline $\begin{array}{l}3000 \text { FBR fuel } \\
\text { pins }\end{array}$ & 0.0845 & 93 & b & 44 & - \\
\hline 5 FBR assemblies & 5.82 & 3 & 1 & 2 & 1 \\
\hline 20 cans ATR MOX & 0.882 & 4 & 1 & 2 & 1 \\
\hline $\begin{array}{l}1000 \text { ATR pellet } \\
\text { stacks }\end{array}$ & 0.0352 & 11 & 1 & 5 & 1 \\
\hline $\begin{array}{l}3000 \text { ATR fuel } \\
\text { pins }\end{array}$ & 0.0352 & 38 & b & 18 & - \\
\hline 5 ATR assemblies & 10.36 & 5 & 1 & 3 & 1 \\
\hline
\end{tabular}

aHLNCC measurement error standard deviations for fuel assemblies are relatively large; hence, for falsifications of less than $1 \mathrm{~kg}$ of plutonium, the detection probability is less than $95 \%$. At the minimum falsification per item $(\sim 0.89 \mathrm{~kg})$, the detection probability drops to $86 \%$.

bWe calculated only attributes sample sizes, for we assumed that oniy whole pins are removed and that these pins are replaced by pins containing no plutonium. 


\section{Containment/Surveillance Measures}

Containment/surveillance measures, such as film cameras, closed-circuit television, and seals, are employed to provide continuous knowledge that materials previously measured by an inspector remain intact, to monitor for movements of material at undeclared times, and to confirm that containments are not breached. Containment/surveillance measures employed by IAEA inspectors at our reference facility consist primarily of seals applied to material containers or fuel assemblies to ensure the integrity of previously verified material quantities.

Seals applied to cans of materials are generally the type $\mathrm{E}$ metallic seals consisting of a wire and two metal caps, which are applied by looping the wire through the object to be sealed and securing the ends of the wire between the two caps. Metallic seals are applied to cans of MOX powder and cans of scrap after the material contents have been verified by an inspector. A seal such as the fuel assembly identification device (FAID) might be applied to finished assemblies by sealing the mechanical link holding the fuel assembly together to monitor possible tampering with the assembly. Integrity of the seal is verified by applying an ultrasonic transducer to obtain a unique response. An alternative measure is to store the fuel assemblies in canisters and apply seals to these canisters.

Aithough surveillance measures are not currently used by the IAEA at fuel fabrication facilities, there are some potential applications that should be considered as part of the safeguards approach. The principal use of surveillance at this facility is to monitor selected KMPs to ensure that materiai transfers are consistent with the State's Inventory Change Reports. In such areas where canisters of MOX powder cans are stored for receipt or shipment, film-camera surveillance provides additional confirmation that the State has reported all movements of these items. Similarly, fiim-camera surveillance may be applicable for monitoring inventory changes in an area where fuel assemblies are stored before shipment. 


\section{v. VERIFICATTON BY CALCULATION OF (MUF-D) AND DETECTION PROB- ABILITY}

Attributes/variables sampling as a verification procedure was discussed in Sec. IV. A second generic verification procedure, built around the D statistic, is discussed here. One distinction of the procedure is that all instruments used are typically of good quality; there is no "attributes" instiument contributing data of marginal quality. A second distinction is that comparisons are not made on an item-by-item basis. Instead, observed differences are averaged and, since the uncertainty in the average is relatively low because poorer quality data are avoided, sensitivity exists to detect discrepancies.

Specifically, the procedure is as follows. The items of material at the facility are divided into strata. Here, a stratum is a collection of like elements, such as the FBR pellet stacks. Stratification is not strictly necessary for developing an inspection plan, but it is useful when material amounts and measurement uncertainties vary widely depending on the items involved. Within each stratum, a sample of items is selected and measured by the inspector. The average observed discrepancy between inspector measurements and operator-declared values is computed and extrapolated to estimate the total discrepancy for the stratum. Adding such estimates over all the strata yields the D statistic.

Once the D statistic is calculated, it is typically combined with the reported MUF. The resulting value, (MUF-D), estimates the total loss of material whether data have been falsified or not. If (MUF-D) is sufficiently far from zero, there is evidence of loss of material. More details regarding (MUF-D) can be found in Appendix $\mathrm{C}$ and in Ref. 25.

Because of the extensive calculations required, sampling plans for (MUF-D) were not developed for the entire MOX facility in this report. Instead, calculations were made for 11 strata, which constitute most facility activity (they account for $\sim 97 \%$ of the plutonium in the MOX line). A D statistic is computed for the 11 strata only and combined with associated contributions to MUF. Those contributions to MUF form MUF ${ }^{*}$, where MUF $=$ MUF $^{*}+$ remainder, and the remainder term involves only minor streams. Thus, the statistic of interest is (MUF $\left.{ }^{*}-D\right)$.

Because the 11 strata do not form a closed system around which a balance can be closed, $\mathrm{MUF}^{*}$ does not have expected value, $\mathrm{E}(\mathrm{MUF})^{*}$, equal to zero. Nonetheless, developing a reduced sampling plan to minimize the variance of (MUF ${ }^{*}-\mathrm{D}$ ) 
subject to resource constraints is quite useful. In a complete sampling regime, the minor streams would receive minor attention, whereas the 11 strata would be inspected in a manner similar to that in the reduced plan. Sample sizes in the reduced plan are meaningful compared with those in the complete situation, because they indicate which strata need the most effort and what overall level of performance is achieved for a given amount of money.

In the following sections, we are more specific. We discuss a method for calculating optimum sample sizes for different inspector resources, propose different loss scenarios, and finally, calculate the detection probability to be expected, given the sample sizes for each stratum arid the special nuclear material (SNM) loss from those same strata.

\section{A. Determination of Inspector's Sample Sizes}

Before we discuss determination of inspector's sample sizes, we must decide which of the 4 transfer strata and 28 inventory strata the inspector should include in his verification efforts. Many of these strata are waste streams or laboratory samples that contain much less than $8 \mathrm{~kg}$ of plutonium. The following 11 strata were chosen for calculation of $\left(\mathrm{MUF}^{*}-\mathrm{D}\right)$ :

- KMP-1 168 cans of MOX/21 days at $1.1025 \mathrm{~kg} \mathrm{Pu} / \mathrm{can}$.

- KMP-2 1092 FBR pellet stacks $/ 21$ days at $0.0845 \mathrm{~kg} \mathrm{Pu} /$ stack.

- KMP-4 2604 ATR pellet stacks $/ 21$ days at $0.0352 \mathrm{~kg} \mathrm{Pu} / \mathrm{stack}$.

- KMP-A(6) 20 cans, FBR blended MOX powder at $3.143 \mathrm{~kg} \mathrm{Pu} / \mathrm{can}$.

- KMP-B $1500 \mathrm{FBR}$ pellet stacks at $0.0845 \mathrm{~kg} \mathrm{Pu} /$ stack.

- KMP-C 3000 FBR pins at $0.0845 \mathrm{~kg} \mathrm{Pu} /$ pin.

- KMP-D 5 FBR fuel assemblies at $5.82 \mathrm{~kg} \mathrm{Pu} /$ assembly.

- KMP-A(6) 20 cans, ATR blended MOX powder at $0.88 \mathrm{~kg} \mathrm{Pu} / \mathrm{can}$.

- KMP-B 1000 ATR pellet stacks at $0.0352 \mathrm{~kg} \mathrm{Pu} / \mathrm{stack}$.

- KMP-C 3000 ATR pins at $0.0352 \mathrm{~kg} \mathrm{Pu} / \mathrm{pin}$.

- KMP-D 5 ATR fuel assemblies at $10.36 \mathrm{~kg} \mathrm{Pu} /$ assembly.

The inspector draws a random sample from each of these strata for independent measurement and, for each stratum, combines his measurements with the operator's declared values for the same items. He averages the difference and extrapolates this difference over the total number of operator measurements as called for in the definition of the $\mathrm{D}$ statistic. He can then determine (MUF $\left.{ }^{*}-\mathrm{D}\right)$. 
Various aspects of the problem of optimal allocation of IAEA inspector resources for safezuarding nuclear facilities have been discussed (see Ref. 27 and the many papers zilied there). The specific problem addressed here is the determination of the samp'e sizes for the different strata that will minimize the standard deviation of (MUF ${ }^{*}-\mathrm{D}$ ) (assuming no loss of plutonium) for a given amount of money available to draw the samples and make the independent measurements. This problem is also discussed in the IAEA Technical Manual. ${ }^{25}$ In this particular case, the inspector's sample sizes were determined by minimizing the variance of the 11 strata chosen subject to monthly cost constraints. The assumed inspector costs per measurement are shown in Table X. A plot of $\sigma_{\left(M U F^{*}-D\right)}$ against available dollars is shown in Fig. 5. Note that as the available resources increase from $\$ 10,000$ to $\$ 35,000$, $\sigma\left(M_{U F}^{*}{ }^{*}-\mathrm{D}\right)$ decreases by about $2.5 \mathrm{~kg}$ of plutonium; increasing the resources from $\$ 35,000$ to $\$ 45,000$ decreases $\left.\sigma_{(M U F}{ }^{*}-D\right)$ by only another $0.3 \mathrm{~kg}$ of plutonium. Several additional constraints were placed on the values of the inspector's sample sizes to carry out the optimization calculation. All sample sizes were required to be $\geq 1$, and sample sizes for KMP-A(6) for both FBR and ATR cans of MOX powder were required to be $\leq 20$ because there are only 20 cans. In addition, sample sizes for KMP-D were required to he $\leq 5$ because there are only 5 FBR and ATR fuel assemblies in the inventory.

Solutions for the optimal sample sizes can be pursued as an exercise in integer programming. Rounding procedures (that is, minimizing without the integer constraint and then rounding off to the nearest integer values) also work well here because of the smooth nature of the object function. In Table XI, sample sizes for

TABLE X

\section{ASSUMED INSPECTOR COST PER MEASUREMENT}

\begin{tabular}{|c|c|c|}
\hline KMP & $\begin{array}{l}\text { Mass Measure- } \\
\text { ment Cost } \\
\text { (\$) }\end{array}$ & $\begin{array}{c}\text { Concentration } \\
\text { Measurement Cost } \\
(\mathbf{S}) \\
\end{array}$ \\
\hline $1,2,4$ & 30 & 500 \\
\hline$A(6)$ & 30 & 150 \\
\hline B & 30 & 200 \\
\hline C & - & 200 \\
\hline D & -- & 500 \\
\hline
\end{tabular}




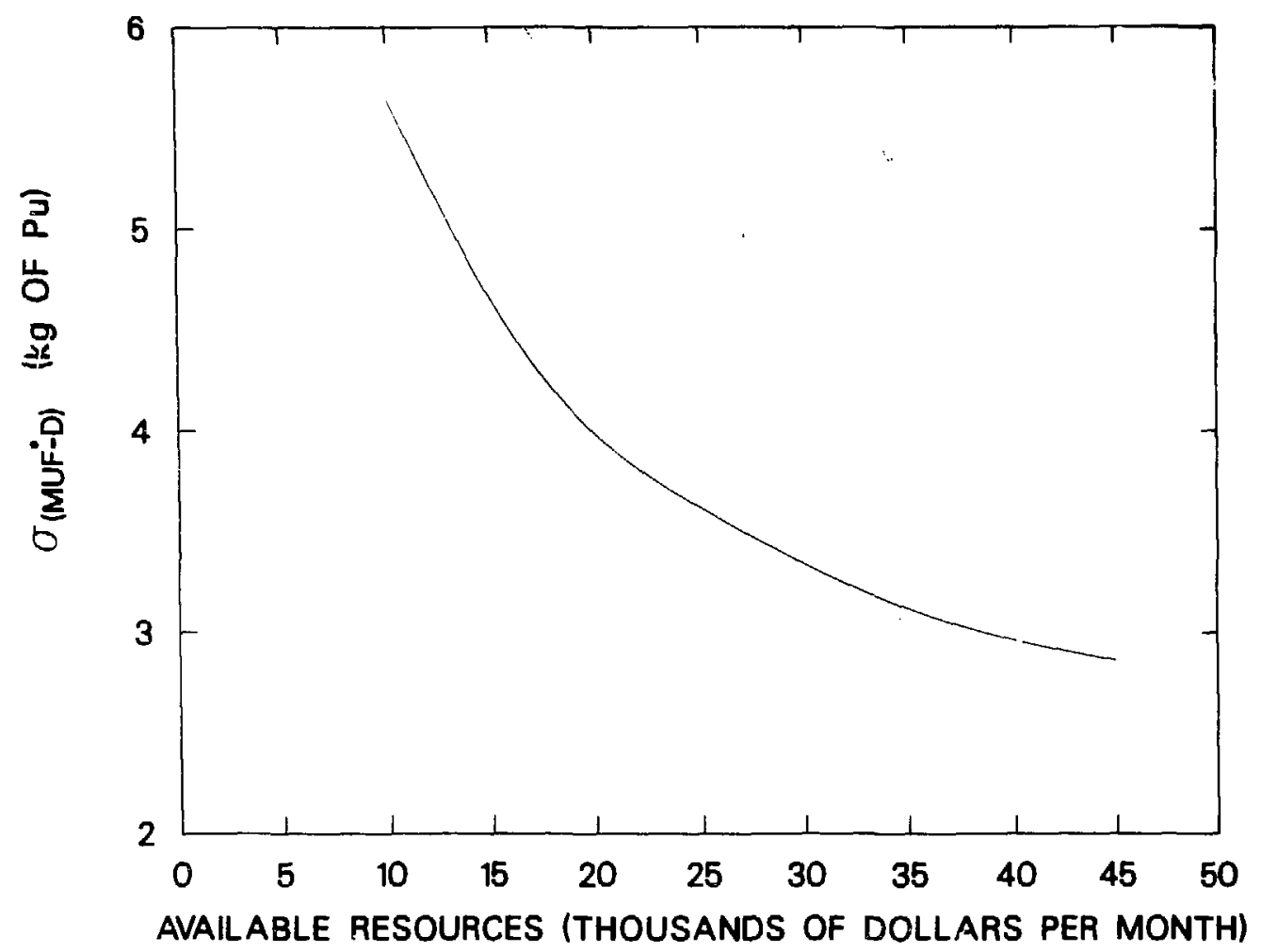

Fig. 5. Resources available vs $\sigma_{\left(M U F^{*}-D\right)}{ }^{*}$

each stratum for two values of available dollars and the corresponding two no-loss values of $\sigma_{\left(M U F^{*}-D\right)}$ are given. The input and output transfers require chemical (destructive) analysis and mass measurements to determine plutonium content, so both sample sizes are given. Inventory measurements are by NDA methods.

\section{B. $\quad\left(M U F^{*}-D\right)$ and Detection Probabilities for Different Loss Scenarios}

After determination of inspector's sample sizes, SNM falsification scenarios can be specified and $\left(\mathrm{MUF}^{*}-\mathrm{D}\right)$ for each loss scenario calculated, along with the corresponding detection probabilities. As pointed out in Appendix $D$, when the inspector's sample size and/or the number of falsified items is small, the (MUF ${ }^{*}-D$ ) statistic can be quite nonnormal, and it is not adequate in such cases to approximate detection probabilities using a normality assumption. In some of the loss scenarios described belcw, the number of falsified items is small and, in addition, the inspector's sample sizes are small. As a result, values of $\left(\mathrm{MUF}^{*}-\mathrm{D}\right)$ were determined by computer simulation of both the operator's and inspector's measurement errors. The 
TABLE XI

INSPECTOR'S SAMPLE SIZES FOR 11 MOX-LINE STRATA FOR TWO VALUES OF AVAILABLE RESOURCES

Sample Sizes/Month

\begin{tabular}{|c|c|c|c|c|}
\hline \multirow{3}{*}{ Stratum } & \multirow{2}{*}{\multicolumn{2}{|c|}{ Resources $=\$ 10,000 /$ month }} & \multirow{2}{*}{\multicolumn{2}{|c|}{ Resources $=\$ 35,000 /$ month }} \\
\hline & & & & \\
\hline & $\begin{array}{c}\text { Mass } \\
\text { Measurements }\end{array}$ & $\begin{array}{l}\text { Concentration } \\
\text { Measurements }\end{array}$ & $\begin{array}{c}\text { Mass } \\
\text { Measurements } \\
\end{array}$ & $\begin{array}{l}\text { Concentration } \\
\text { Measurements }\end{array}$ \\
\hline $\begin{array}{l}\text { Input of } 168 \text { cans } \\
\text { of MOX }\end{array}$ & 1 & 1 & 1 & 4 \\
\hline \multicolumn{5}{|l|}{ Output of 1092} \\
\hline $\begin{array}{l}\text { Output of } 2604 \\
\text { ATR stacks }\end{array}$ & 1 & 1 & 1 & 3 \\
\hline $\begin{array}{l}\text { Inventory of } 20 \\
\text { cans of FBR MOX }\end{array}$ & 7 & - & 20 & - \\
\hline $\begin{array}{l}\text { Inventory of } 1500 \\
\text { FBR stacks }\end{array}$ & 12 & - & 47 & - \\
\hline $\begin{array}{l}\text { Inventory of } 3000 \\
\text { FBR pins }\end{array}$ & 8 & - & 31 & - \\
\hline $\begin{array}{l}\text { Inventory of } 5 \\
\text { FBR assemblies }\end{array}$ & 2 & - & 5 & - \\
\hline $\begin{array}{l}\text { Inventory of } 20 \\
\text { cans of ATR MOX }\end{array}$ & 2 & - & 8 & - \\
\hline $\begin{array}{l}\text { Inventory of } 1000 \\
\text { ATR stacks }\end{array}$ & 3 & - & 13 & - \\
\hline $\begin{array}{l}\text { Inventory of } 3000 \\
\text { ATR pins }\end{array}$ & 3 & - & 13 & - \\
\hline $\begin{array}{l}\text { Inventory of } 5 \\
\text { ATR assemblies }\end{array}$ & 3 & - & 5 & - \\
\hline$\left.\sigma_{(M U F}{ }^{*}-\mathrm{D}\right)(k$ & (u) & & 3.11 & \\
\hline
\end{tabular}


falsification was assumed to occur only in the operator's declared value of the plutonium concentration of an item and not in his declared value of the mass (although detection probabilities for the latter case can also be calculated). Using the two sets of sample sizes for the two different resource values in Table XI, we assumed detection occurred if a value of $\left(\mathrm{MUF}^{*}-\mathrm{D}\right)$ was greater than 1.96 times the corresponding value $\sigma_{\left(M_{U} F^{*}-D\right)}$, also given in Table XI.

Values of $\left(M^{\prime}{ }^{*}-D\right)$ and the corresponding detection probabilities were determined for a variety of loss scenarios. A selection of these scenarios is presented in Table XII, along with the estimated detection probabilities for two values of inspector resources per month: $\$ 10,000$ and $\$ 35,000$. Because IAEA goals may be unachievable in large facilities even if all items are inspected, ${ }^{28}$ the objective here is to quantify the sensitivity attained given reasonable expenditures. Detection probability results were obtained by simulation.

For falsification scenarios designed to defeat the inspector's measurement sensitivity, detection probabilities can be adequately approximated using normal theory. As an example, consider the $\$ 10,000 /$ month case. Here, $\sigma_{\left(\mathrm{MUF}^{*}-\mathrm{D}\right)}=5.64 \mathrm{~kg}$ when there is no falsification and the threshold for an alarm is $(1.96)(5.64)-E\left(M U F^{*}\right)$ $=11.05-E\left(M^{*}{ }^{*}\right) \mathrm{kg}$. Given a falsification scenario with nearly all items in one or more strata falsified so that the total falsification is $8 \mathrm{~kg}$, the detection probability is roughly

$$
\begin{aligned}
\mathrm{P}\left\{\left[\mathrm{MUF}^{*}-\mathrm{E}\left(\mathrm{MUF}^{*}\right)-\mathrm{D}\right]>11.05\right\} & =\mathrm{P}\left\{\frac{\left[\left(\mathrm{MUF}^{*}-\mathrm{E}\left(\mathrm{MUF}^{*}\right)-\mathrm{D}\right]-8\right.}{\sigma_{\left(\mathrm{MUF}^{*}-\mathrm{D}\right)}}, \frac{11.05-\mathrm{E}\left(\mathrm{MUF}^{*}\right)-8}{5.64}\right\} \\
& \simeq \Phi(-3.05 / 5.64) \\
& =298,
\end{aligned}
$$

where $\Phi$ is the unit normal integral. For the $\$ 35,000 /$ month case, the corresponding calculation gives $73 \%$. In Table XII, falsification scenarios designed to defeat the inspector's measurement sensitivity (scenarios 3-5) lead to detection probabilities comparable to these figures.

Unfortunately, the above calculations are not valid for scenarios designed to defeat the sampling. As described in Appendix D, (MUF-D) need not be normally distributed. For example, scenario $l$ at $\$ 35,000$, where 8 of the 168 input transfers are falsified and the inspector samples 4 of them, leads to a detection probability of 
TABLE XII

FALSIFICATION SCENARIOS AND DETECTION PROBABILITIES ${ }^{a}$

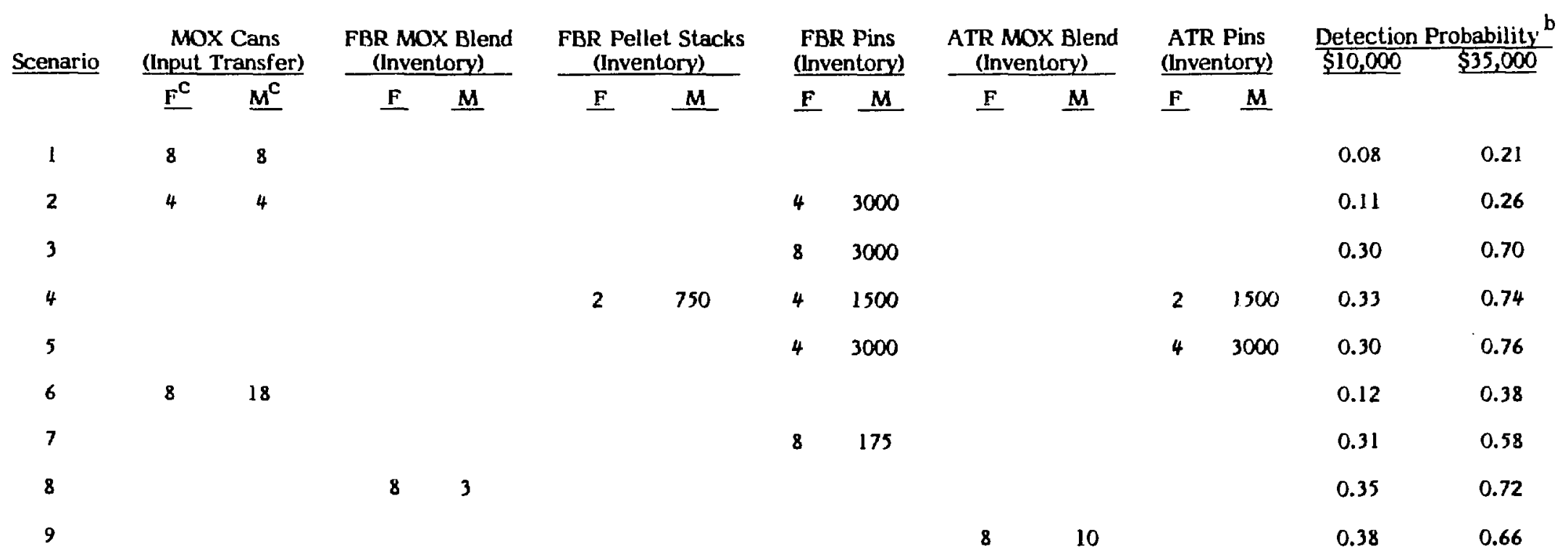

an the simulations to calculate detection probabilities, 11 strata were included. Five strata that were part of the simulation but not part of the tabulated data here are (1) FBR pellet stacks (output transfers), (2) ATR pellet stacks (output transfers), (3) FBR assemblies (inventory), (4) ATR pellet stacks (inventory), and (5) ATR assemblies (inventory).

betection probabilities were calculated for two resource allocations for inspection- $\$ 10,000$ and $\$ 35,000$ per month.

$C_{F}$ is falsification in kilograms of plutonium per stratum, and $M$ is the number of items falsified in the stratum. 
$\sim 21 \%$ vs the $73 \%$ above. The relatively small $21 \%$ probability arises from the inspector's $\sim 82 \%$ chance of not sampling any falsified items together with the $\sim 2.5 \%$ false-alarm rate.

Thus, sensitivity depends not only on the goal quantity $(8 \mathrm{~kg})$ but also on the falsification scenario. When sample sizes and measurement uncertainties are as described earlier, it is much more attractive from the divertor's point of view to falsify in a manner that attempts to defeat the sampling than to falsify in a manner that attempts to defeat the measurement sensitivity. Loss scenarios 1, 2, 6, and 7 illustrate this point. In each case, the number of falsified items is small compared with the number of available items per month. Resulting detection probabilities are low. In scenarios 3, 4, and 5, a large number of items from the chosen strata are falsified; hence, the inspector's sample will be nearly normally distributed, and the detection probabilities are approximately the values one would calculate using the normality assumption.

Scenarios 8 and 9 , at $\$ 35,000 /$ month, illustrate the effects of measurement noise on the $\left(M_{U C F}{ }^{*}-D\right)$ calculation. Inspector's sample sizes for the strata of these two scenarios are 20 cans of blended FBR MOX (out of 20 possible) and 8 cans of blended ATR MOX (out of 20 possible). Because the inspector verifies all 20 cans of the FBR blended MOX in scenario 8, detection of a falsification of $2.67 \mathrm{~kg}$ of plutonium from each of 3 cans would be virtually certain if he were dealing with only this stratum. However, measurement noise contributed by the other (unfalsified) strata to $\left(\mathrm{MUF}^{*}-\mathrm{D}\right)$ reduces the detection probability to $72 \%$. 


\section{v. DISCUSSION AND CONCLUSIONS}

This reference MOX facility differs from conventional MOX fuel fabrication facilities in two important respects. First, this MOX facility has neither a conversion line at the front end nor does it use pure $\mathrm{PuO}_{2}$ as a feed material. The input to this facility is a mixed oxide of uranium and plutonium containing $50 \% \mathrm{PuO}_{2}$ originating from a nearby co-conversion plant or fuel reprocessing plant. The second major difference in this facility is that it has two storage vaults with very large inventories of plutonium as MOX, one at the front end storing feed materials and the other at the product end storing completed fuel assemblies. Developing a strategy for safeguarding such a facility requires identification of key elements of IAEA safeguards specific to this facility and preparing a facility attachment and appropriate safeguards arrangements to meet the special requirements of this facility. ${ }^{3}$

The key elements of IAEA safeguards for such a MOX fuel fabrication facility include the following:

(1) a materials accountancy and reporting system approved by the IAEA;

(2) an agreed-upon set of procedures to audit records;

(3) provisions to install and maintain surveillance equipment at strategic points;

(4) use of containment devices such as seals for all feed material, storage containers, and fuel-assembly storage canisters in the vault;

(5) use of well-established, modern measurement methods for flow and inventory measurements by the operator;

(6) use of compatible modern measurement methods for verification by IAEA;

(7) availability of IAEA inspectors at the facility at all times and access to this facility by the IAEA when verification activities are needed;

(8) monthly verification of operator's materials balance to test for abrupt and protracted diversion;

(9) semiannual physical inventory and verification after an orderly shutdown and cleanout of process equipment;

(10) inspector access to operator's NRTA data;

(11) attributes and variables measurements to verify transfers and items in interim storage;

(12) use of containment and surveillance as secondary measures for verifying vault storage; 
(13) attributes measurements for physical inventory verifications for feed and product storage vaults; and

(14) use of the (MUF-D) statistic for IAEA verification.

Detailed examination of key elements of the safeguards approach for this facility suggests that for the feed and product storage areas, flow verifications and periodic physical inventory verifications are two important features of IAEA safeguards implementation. These can be achieved by providing access to this facility when verification activities are needed and by having an IAEA inspector available at the facility at all times. A properly designed containment/surveillance system and maintenance of continuity of knowledge regarding the movement of materials would complement the safeguards measures and assist LAEA in its verification activities. For the process areas of MBA-2, flow verifications, monthly in-process inventory measurements, accurate determination of plutonium contents of the scrap and waste shipped out of the MBA, and physical inventory verifications are all important aspects of IAEA safeguards. The value of containment and surveillance at this process area is limited, although the existing surveillance system used by the operator for remote processing can be used to augment safeguards elements, such as in-process inventory verification. Surveillance devices can also be used effectively during inspections and physical inventory verifications to ensure that each item is inventoried without duplication, the integrity of the samples is preserved, and the instruments used for verifications are not subjected to tampering.

Although this MOX fuel fabrication facility is different from other existing facilities, there are some special features at this facility that have safeguards advantages:

(1) remote operation of major parts of the processes at this facility, thus limiting access to materials and process areas;

(2) near-real-time materials accountancy and computerized data management system used by the operator and accessible to the LAEA;

(3) separation of the process MBA from storage vaults;

(4) the vault storage limited to items with IAEA seals as a containment;

(5) the ability to retrieve and place all the materials, except those in calciners, in interim storage vaults at the end of each working day and the ability to carry out attributes measurements during transfer into and out of these interim storage vaults;

(6) continuous presence of an IAEA inspector to facilitate inspections and inventory verifications with minimal process disruptions; and 
(7) provisions of INFCIRC/153, which would allow routine inspection effort of up to -2100 man-days/yr for this facility.

Also, there are features of this facility that would make safeguards-related materials accountancy and the LAEA inspections and verifications rather demanding and laborious. Some of these features also contribute to highly inventory-dominated variances for materials balance closings. The features of this facility that contribute to materials accountancy concerns include

(1) multiproduct process lines for various types of fuels;

(2) large inventories of plutonium as MOX in the process areas;

(3) high radiation field within the process area, causing large uncertainties in NDA measurements carried out at this location;

(4) limited access to materials for verification measurements;

(5) long residence time of materials within the process areas; and

(6) very large inventories of feed materials and products in the two storage vaults.

IAEA inspection goals (material quantities and detection times) determine the frequencies of inspections and verification activities. In order to identify abrupt diversions for this facility, the inspector must perform at least one inspection per month to verify material flows and in-process inventories. Sensitivity analysis carried out for the process MBA suggests that a few items of in-process inventory dominate the variance of the materials balance for this MBA (see Sec. III). An increase in these inventories would further increase the variance. Also, we should add that, in developing measurement uncertainties for these calculations (Table II), we made rather optimistic assumptions, and it is therefore possible to have a higher variance value than we reported here. These optimistic measurement uncertainties lead to a $\sigma$ of MUF value for MBA-2 for a 21 -day accounting period of $1.47 \mathrm{~kg}$ of plutonium, which is $0.8 \%$ of throughput. Current practices at some fuel fabrication facilities, where the facility operators use results of high-quality chemical analyses of fuel pellets in accounting for fuel pins and fuel assemblies, would show a more optimistic $\sigma$ value of $0.9 \mathrm{~kg}$ of plutonium for this process MBA. In addition, the sensitivity of the materials accounting system for detecting protracted losses of materials was quantified assuming losses evenly spread over several inventory periods during a year. These sensitivities were calculated assuming monthly instrument calibrations. For a $5 \%$ false-alarm rate, uetection probabilities exceed $98 \%$ for all of the loss scenarios considered. 
Various aspects of the problem of optimal aliocation of inspector resources are considered in Sec. V, where a generic verification procedure built around the D statistic is discussed. Because the computations are rather lengthy, the calculations in Sec. $V$ incorporate only those strata that constitute major transfers and inventories (see Sec. II.C). Results of Sec. V indicate that the detection probabilities for (MUF-D) vary over a wide range. The lowest detection probabilities correspond to scenarios where the smallest number of items are falsified to obtain a goal quantity and the inspector's sample size is small. In general, this type of behavior can be anticipated when resource constraints preclude extensive inspection. Thus, the scenarios considered give a range of detection probabilities from $8 \%$ to $76 \%$. When large numbers of items are falsified to defeat the measurement system for verification, the performance can be reasonably approximated using normality assumptions. In these cases, the detection probabilities are relatively high compared with the probabilities for detecting falsification designed to defeat sampling plans. 


\section{ACKNOWLEDGMENTS}

The authors wish to acknowledge the assistance of Richard Schneider of Exxon Nuclear Company, Inc.; Frank Houck of the U.S. Arms Control and Disarmament Agency; Cookie Ong of the U.S. Nuclear Regulatory Commission; and Jack Markin of the Los Alamos National Laboratory for their valuable comments and suggestions during the preparation of this report. We acknowledge the computer assistance provided by John F. Hafer and the graphics assistance provided by Lynne Y. Williams.

\section{REFERENCES}

1. "The Structure and Content of Agreements Between the Agency and States Required in Connection with the Treaty on the Non-Proliferation of Nuclear Weapons," International Atomic Energy Agency document INFCIRC/153 (corrected) (1972).

2. K. K. S. Pillay and D. Stirpe, "Key Elements for Safeguarding a MOX Fuel Fabrication Facility Against Abrupt Diversions," Los Alamos National Laboratory, Safeguards Systems Group, document Q-4/86-230 (April 1986).

3. "IAEA Safeguards Implementation at Nuclear Fuel Cycle Facilities," International Atomic Energy Agency report IAEA/SG/INF/6 (1985).

4. B. Keisch and J. B. Sanborn, "Case Study Application of the Safeguards Effectiveness Assessment Methodology to a Mixed Oxide Fuel Fabrication Facility," Brookhaven National Laboratory report ISPO-212 (February 1984).

5. W. Bahm, T. Shea, and D. Tolchenkov, "Safeguards Considerations for Mixed Oxide Fuel Element Fabrication Facilities," International Atomic Energy Agency report STR-89 (October 1979).

6. J. P. Shipley, D. D. Cobb, R. J. Dietz, M. L. Evans, E. P. Schelonka, D. B. Smith, and R. B. Walton, "Coordinated Safeguards for Materials Management in a Mixed-Oxide Fuel Facility," Los Alamos Scientific Laboratory report LA-6536 (February 1977).

7. D. D. Cobb, "Material Flow and Inventory Data for a 200-Tonne Per Year Mixed-Oxide Fuel Fabrication Plant," Los Alamos Scientific Laboratory document LA-UR-77-2490 (October 1977).

8. "Some Safeguards Considerations for Mixed Oxide Fuel Element Fabrication Facilities," International Atomic Energy Agency report AG-244 (Draft) (February 1980).

9. D. R. Rogers, Ed., "Handbook of Nuclear Safeguards Measurement Methods," US Nuclear Regulatory Commission report NUREG/CR-2078 (September 1983), Chaps. 2, 4, and 6. 
10. W. L. Delvin, Ed., "Analytical Chemistry Laboratory Manual," Hanford Engineering Development Laboratory report MG-28 (October 1978), Vol. 2.

11. "1985 Annual Book of ASTM Standards," Vol. 12.01, Method C-698 (American Society for Testing and Materials, Philadelphia, Pennsylvania, September 1985).

12. W. Theis, "Typical LAEA Inspection Procedures for Model Plant," in "International Training Course on Implementation of State Systems of Accounting for Control of Nuclear Materials, October 17-November 4, 1983, Santa Fe, New Mexico and Richland, Washington," C. R. Hatcher and H. A. Smith, Jr., Comps., Los Alamos National Laboratory report LA-10135-C (June 1984).

13. "Safeguards Effectiveness Evaluation Methodology--Case Study: Application to a Mixed Oxide Fuel Fabrication Facility, Vol.1: Design Assessment," Science Applications, Inc., draft report SAI 01580-368 (August 1980).

14. J. E. Glancy, "Design Information Questionnaire for a Model Mixed Oxide Fuel Fabrication Facility," Brookhaven National Laboratory report BNL-21408 (May 1976).

15. D. Reilly and R. Augustson, "A Simulated Physical Inventory Verification Exercise at Mixed-Oxide Fuel Fabrications Facility," 7th ESARDA Symposium on Safeguards and Nuclear Materials Management, Liege, Belgium (1985), pp. 121 125.

16. L. Cowder and H. O. Menlove, "Neutron Coincidence Counter for MOX Fuel Pins in Storage Trays: Users' Manual," Los Alamos National Laboratory repurt LA-9493-M (ISPO-178) (August 1982).

17. H. O. Menlove, E. L. Adams, E. Dahn, and A. Ramalho, "Plutonium Canister Counter Operations and Procedures Manual," Los Alamos National Laboratory report LA-10615-M (ISPO-216) (February 1986).

18. M. S. Krick, H. O. Menlove, and A. Ramalho, "Birdcage Neutron Coincidence Counter Manual," Los Alamos National Laboratory report LA-10430-M (ISPO-234) (July 1985).

19. J. E. Foley and G. E. Bosler, "High-Level Neutron Coincidence Counter (HLNCC) Implementation: Assay of Plutonium Content of Mixed-Oxide Fuel Assemblies," Los Alamos National Laboratory report LA-9318-MS (ISPO-171) (April 1982).

20. E. R. Martin, D. F. Jones, and J. L. Parker, "Gamma-Ray Measurements with Segmented Gamma Scan," Los Alamos Scientific Laboratory report LA-7059-M (December 1977).

21. M. H. Campbell and R. E. Tomlinson, "Safeguarded Fabrication and Reprocessing (SAFAR)," Electric Power Research Institute report NP-2631 (November 1982).

22. R. J. Jones, "Safeguarding Low Enriched Uranium Conversion and Fuel Fabrication Facilities," International Atomic Energy Agency report STR-157 (November 1984). 
23. J. Lovett, "Safeguards for the Fabrication of MOX Fuel," International Atomic Energy Agency report STR-182 (February 1985).

24. W. W. Strohm, S. Fiarman, and R. B. Perry, "A Demonstration of the In-field Use of Calorimetric Assay for LAEA Inspection Purposes," Mound Facility, Monsanto Research Corporation, report MLM-3278(OP) (1 185).

25. "IAEA Safeguard́s Technical Manual, Part F, Statistical Concepts and Techniques, Vol. 3," International Atomic Energy Agency document IAEA-TECDOC261 (1982).

26. D. Stirpe and R. R. Picard, "Improved Sample Size Determination for Attributes and Variables Sampling," Nuclear Materials Management XIV (Proceedings Issue), 454-460 (1985).

27. L. G. Fishbone, "Optimal Allocation of Safeguards Inspection Resources for Nuclear Fuel Cycle," Nuclear Materials Management XIV(2), 22-36 (1986).

28. M. J. Canty, "Comments on Inspection Goal Criteria for Material Accountancy," ESARD Bulletin 11, 6-7 (1986). 


\title{
APPENDIX A
}

\section{MBA STRUCTURE OF THE MOX FUEL FABRICATION LINES}

by

\author{
K. K. S. Pillay
}

The MBAs of the reference MOX fuel fabrication facility and their structure are described here, alons with those details of material movement across the boundaries that are relevant to materials accountancy and safeguards. The MOX facility consists of three major MBAs as shown in Fig. A-l. Two of these (MBA-l and MBA-3) are storage vaults, and the third one (MBA-2) is the only process MBA. As elaborated in other parts of this report, $M B A-2$ is the most important from the materials accounting point of view. Both accountancy and verification of nuclear materials in this MBA offer most of the challenges to the safeguards system for this facility.

\section{MOX STORAGE VAULT (MBA-1)}

This is the storage area for the MOX received from the co-conversion facility. The co-conversion facility is under IAEA safeguards, and we assume that all shipments of MOX out of this co-conversion plant are under LAEA seals. The MOX shipments are made in sealed canisters; each of these canisters contains four cans of MOX, with each can containing $2.5 \mathrm{~kg}$ of MOX (or $1.25 \mathrm{~kg}$ of $\mathrm{PuO}_{2}$, or $1.102 \mathrm{~kg}$ of plutonium). Therefore, all containers of MOX in this MBA are considered items that have been measured, sealed, and assigned unique identification numbers. We assume that the inventory of this MBA is verified through attributes sampling and measurement. Shipper/receiver differences, if any, are resolved here before the material is transferred to MBA-2 for processing. Because MBA-1 handles materials only as items, no materials balance equation was developed for this MBA.

The design capacity of this vault is for the storage of 1000 canisters of $1: 1$ MOX, or the equivalent of $4.4 \mathrm{Mt}$ of plutonium. The average inventory of this vault is about 200 canisters, or about $880 \mathrm{~kg}$ of plutonium. 


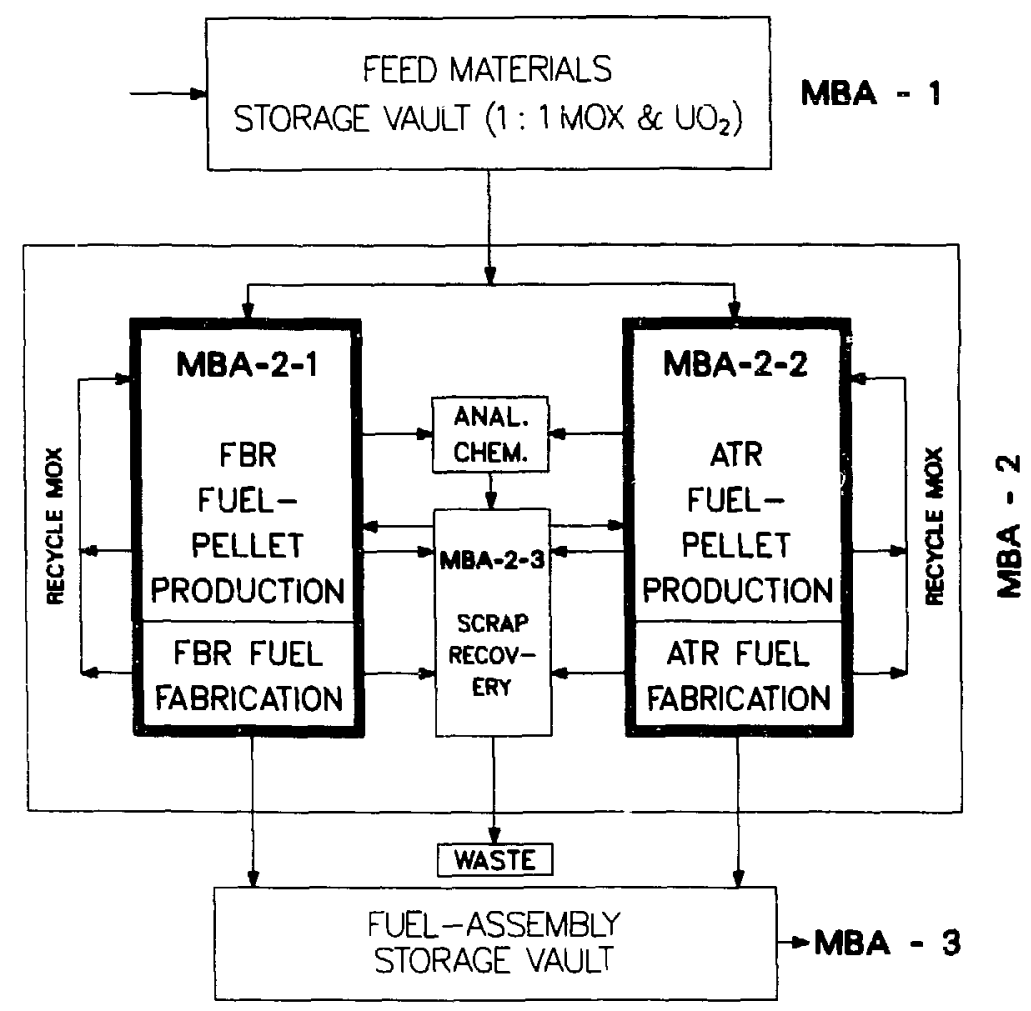

Fig. A-1. Major MBAs of the MOX fuel fabrication facility and subdivisions of process MBÁ-2.

\section{MOX FUEL FABRICATION LINES (MBA-2)}

All the processing at this facility takes places within MBA-2. Here, the input MUX from MBA-1 is blended with uranium oxide (with a ${ }^{235} \mathrm{U}$ abundance of $0.72 \%$ or less) to obtain MOX powder(s) of the desired composition(s). Subsequent processing includes steps leading initially to the production of fuel pellets, which are fabricated into fuel pins before being assembled into fuel assemblies.

There are two independent process lines in this MBA--one manufacturing FBR fuels and the other ATR fuels. In addition, this MBA contains the analytical laboratory and the scrap recovery facility. These three distinct areas of MBA-2 are designated as MBA-2-1, -2-2, and $-2-3$ as shown in Fig. A-1. Approximate values of input and output transfers of materials across these subdivisions of MBA-2 are presented in Figs. A-2, A-3, and A-4. Also, from a materials accounting point of view, the following procedures carried out in this MBA are noteworthy: 


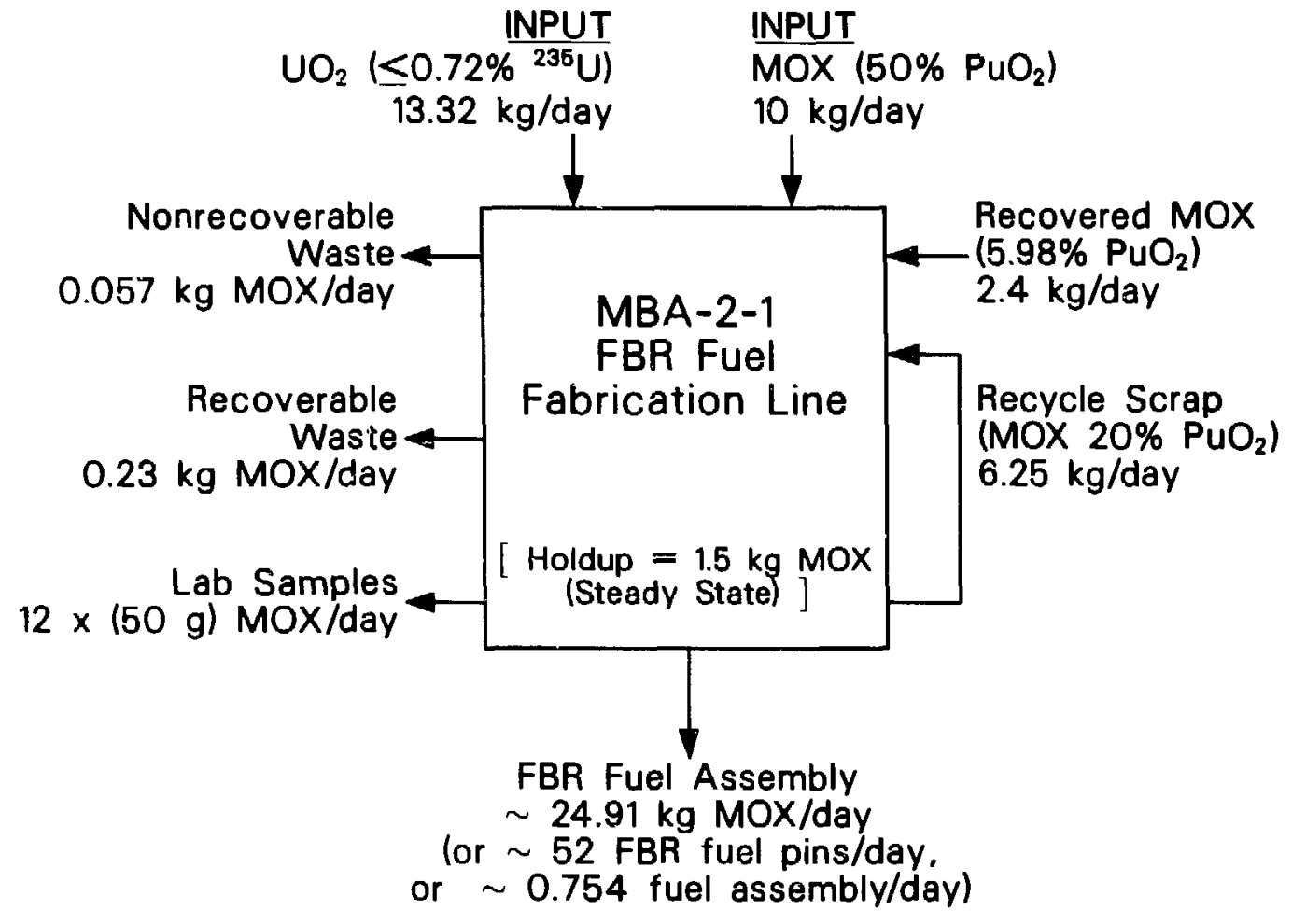

Fig. A-2. Approximate material transfers per day across the boundaries of MBA-2-1 .

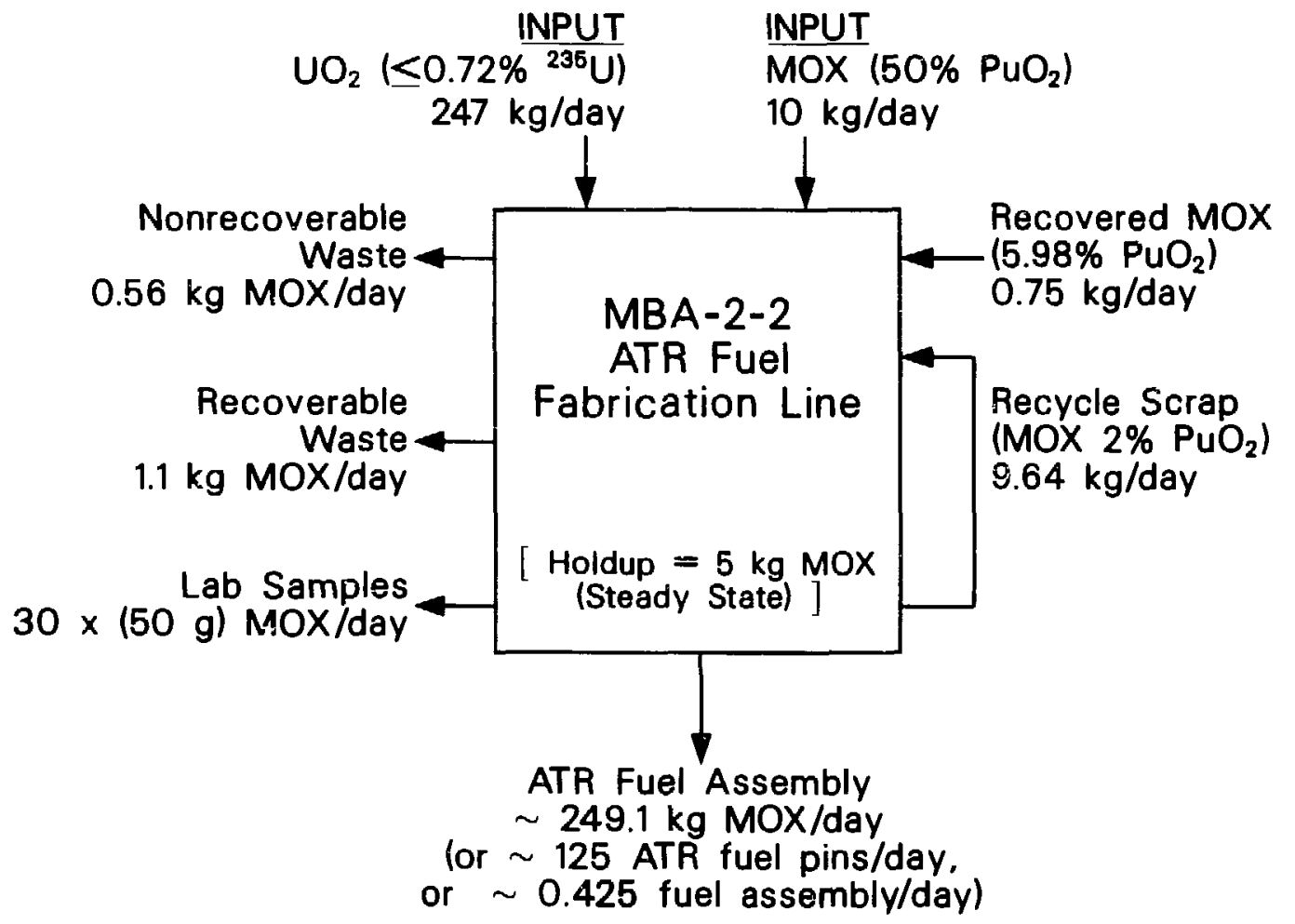

Fig. A-3. Approximate material transfers per day across the boundaries of MBA-2-2. 


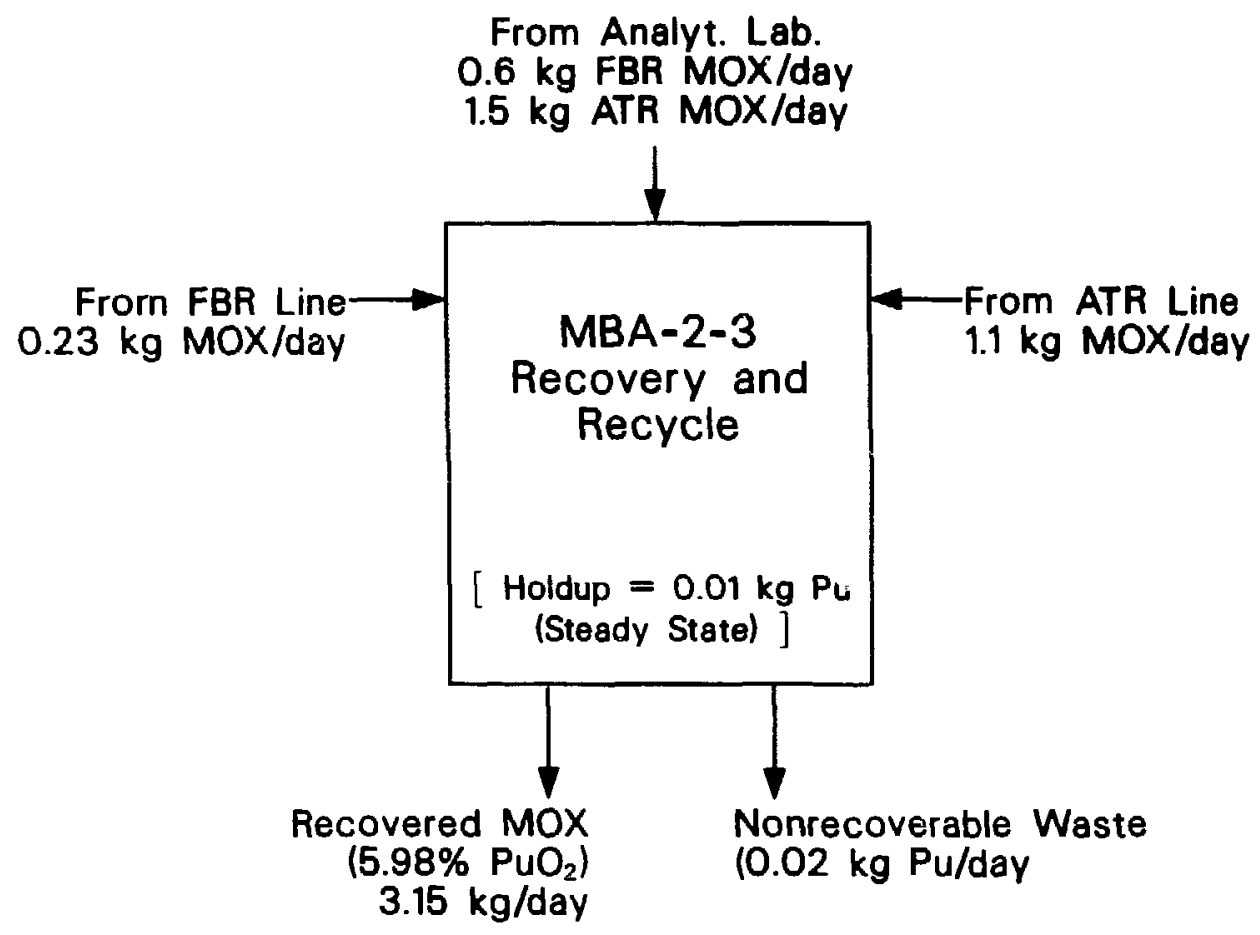

Fig. A-4. Approximate material transfers per day across the boundaries of MBA-2-3.

- All materials, except those in the sintering furnaces, are transferred into interim storage at the end of each day. At the beginning of the next working day, materials needed for processing are transferred back into the process areas from interim storage.

- As a material is transferred into and out of the interim storage, it is weighed, an attribute is measured, and an identification number on the container is read and recorded with a remote scanning device.

- At the 21-day accounting times, markers are placed in the feed lines of the calcining and sintering furnaces to identify and divide the pellet trays of different materials balance periods. Sintered fuel pellets from the current accounting period contained in trays are transferred to interim storage or processed into pellet stacks or pins.

- Recoverable scrap is collected daily from both process lines and combined for the recovery process. The recovered MOX is recycled back into the process lines on a regular basis. 
- Disposable waste is collected daily from both process lines, the analytical laboratory, and the scrap recovery operations. It is packaged in shipping containers, and the plutonium content of each container is measured using NDA techniques. These waste containers are periodically shipped out of MBA-2.

The above procedures are designed to reduce the in-process inventories that are in process equipment at materials balance closings. However, there are over $800 \mathrm{~kg}$ of plutonium distributed in this MBA at materials balance closings.

\section{FUEL-ASSEMBLY STORAGE VAULT (MBA-3)}

This is a vault to store finished fuel assemblies from the process lines in MBA-2. The completed assemblies are placed in special canisters and are inspected and sealed by the IAEA before they are moved into this vault for storage. The vault has a maximum capacity of about 300 fuel assemblies. Normally, this vault has an average inventory of 200 fuel assemblies, with approximately equal numbers of FBR and ATR types. Thus, the average inventory of this vault is about $1600 \mathrm{~kg}$ of plutonium. The inventory in this MBA can be readily verified by item councing, attributes measurements, and checking the integrity of seals placed on the canisters.

\section{MOX FACILITY DESIGN CAPACITY}

The design capacity of this MOX fuel fabrication facility and the average inventory of the three MBAs are summarized in Table A-I. The materials balance for this facility is closed only around MBA-2 because all the materials in MBA-i and -3 are maintained as items under IAEA seals. Although this report considers operating only one shift per day, the throughput of this facility can be increased by operating multiple shifts per day and by reducing residence time of materials in the process lines. 
TABLE A-I

CAPACITY AND AVERAGE INVENTORY OF EACH MBA

MBA No. and Description

MBA-1, storage vault (1:1 MOX)

MBA-2, process area (or fuel fabrication line)

MBA-3, storage vault for fuel assemblies

Total (kg Pu)
Design

Capacity

$\underline{(\mathrm{kg} P \mathrm{Pu}}$

4400

1000

$\underline{2430}$

7930
Average

Inventory

(kg Pu)

882

804

1618

3304 


\section{APPENDIX B}

\section{EXAMPLE VARIANCE CALCULATIONS}

by

D. Stirpe

In this appendix, two example variance calculations that will indicate the procedure used in obtaining two variance results shown in Table IV are given. The two examples chosen are KMP 1 (input MOX powder) and KMP A(6) (cans of blended FBR MOX powder). The first of these is an input transfer term and the second is an inventory term.

The input transfer term can be written as

$$
I=\sum_{i=1}^{N} C_{i}(B X-L X)_{i},
$$

where $\mathrm{C}$ is the plutonium concentration ( $\mathrm{kg} \mathrm{Pu} / \mathrm{kg}$ MOX), BX and $\mathrm{LX}$ are the gross mass and tare mass of the MOX cans, respectively, and $\mathbf{N}$ is the number of measurements made of $\mathrm{C}, \mathrm{BX}$, and LX during the accounting period. If we assume an additive error model for the mass $(\mathrm{X})$ measurements ano a multiplicative error model for the concentration $(\mathrm{C})$ measurements, the variance of $\mathrm{T}$ becomes

$$
\operatorname{Var}(T)=2 \mathrm{NC}^{2} \sigma_{\varepsilon_{\mathrm{X}}}^{2}+[\mathrm{C}(\mathrm{BX}-\mathrm{LX})]^{2}\left(\mathrm{No}_{\varepsilon_{\mathrm{c}}}^{2}+\mathrm{N}^{2} \sigma_{\eta_{\mathrm{C}}}^{2}\right)
$$

In this equation $\sigma_{\varepsilon_{\mathrm{X}}}$ is the random standard deviation of the mass measurements and $\sigma_{\varepsilon_{C}}$ and $\sigma_{\eta_{C}}$ are the random and correlated standard deviations of the concentration measurements, respectively.

For this transfer term, $\mathbf{N}=8$ cans/day times 21 days in the accounting period, or $\mathrm{N}=168$. Also, $\mathrm{C}=0.441 \mathrm{~kg} \mathrm{Pu} / \mathrm{kg} \mathrm{MOX}, \mathrm{BX}=2.75 \mathrm{~kg}$, and $\mathrm{LX}=0.25 \mathrm{~kg}$. The error standard deviations are given in Tables II and III, where $\sigma_{\varepsilon_{C}}=0.36 \%$, $\sigma_{n_{c}}=0.21 \%$, and $\sigma_{\varepsilon_{x}}=0.0002 \mathrm{~kg}$. Substituting these values into the equation for $\operatorname{Var}(T)$ gives $\operatorname{Var}(T)=0.1539 \mathrm{~kg}^{2}$ of plutonium, as shown in Table IV. 
The inventory term is written as an inventory difference:

$$
\text { Beginning Inventory - Ending Inventory }=B I-E I=\sum_{i=1}^{N} x_{i}-\sum_{i=1}^{N} x_{i}^{\prime},
$$

where $\mathbf{N}$ is the number of measurements made of the items in inventory and $\mathrm{X}$ and $\mathrm{X}^{\prime}$ are the beginning and ending measured values of the plutonium content of each item. The variance expression for this inventory difference is

$$
\operatorname{Var}(B I-E I)=2 x^{2} N \sigma_{x}^{2},
$$

where we have assumed that the NDA instrument used to measure the value of $\mathrm{X}\left(\mathrm{X}^{\prime}\right)$ is described by a multiplicative error model. At KMP A(6) for the FBR line, there are $\mathbf{N}=20$ cans of blended MOX powder, each containing $X=3.1434 \mathrm{~kg}$ of plutonium. From Table II, we see that $\sigma_{\varepsilon_{X}}=3 \%$. Substituting these values into the above equation gives $\operatorname{Var}(\mathrm{BI}-\mathrm{EI})=0.3557 \mathrm{~kg}^{2}$ of plutonium, as shown in Table IV.

Similar procedures were followed to obtain the other variance values shown in Table IV. 


\section{APPENDIX C \\ SEQUENTIAL ANALYSIS OF MATERIALS BALANCES}

by

R. R. Picard

This appendix discusses near-real-time accounting at the MOX fuel fabrication facility described in Sec. II of the text. Sensitivity of a standard sequential testing procedure, applied to unfalsified operator data only, is examined for a variety of loss scenarios.

In Sec. I of this appendix, error propagation for $M B A-2$ is reviewed. Mathematical development for the analysis is given in Sec. II, and generic aspects of sequential testing are reviewed in Sec. III.

\section{ERROR PROPAGATION}

As a result of frequent balance closures, the sequence of observed materials balances is inventory-dominated. That is, uncertainties in estimated inventories are much larger than those in the estimated transfers for each materials balance. Combining inventory-dominated materials balances with steady-state plant operation implies that the covariance structure for the sequence of materials balances resembles that for a first-order moving average process of conventional time series. The covariance between successive materials balances is roughly $-0.97 \mathrm{~kg}^{2}$ of plutonium and the covariance between nonsuccessive materials balances is zero because of monthly instrument calibrations.

Several assumptions of the process description tend to produce optimistic results--that is, results indicating better performance of the accounting system than may be achieved. The first assumption is that the process is steady-state. For most measurement error models, so-called systematic errors in estimated inventories "cancel" for steady-state operation, reducing variabilit', from that achieved with the more realistic non-steady-state assumption. The secon, . "nption is that the nonmeasurement contributors to the materials balance are negligible. These contributors, including unmeasured holdup, lead to observed variability in materials balances over time exceeding the variability caused by measurement errors alone, thus 
degrading sensitivity to material loss. The third assumption is that accounting is based on the operator's reported data alone and that the potential for falsification to disguise diversion is ignored.

\section{NOTATION AND DEVELOPMENT}

The sequence of observed materials balances through the $\mathrm{n}^{\text {th }}$ inventory period is denoted $\{\mathrm{MB}(\mathrm{j}) ; \mathrm{j}=1,2, \ldots, \mathrm{n}\}$. It is customarily assumed that

$$
\underset{\sim}{M} \sim N\left(\underline{u}, \Sigma_{n}\right)
$$

where $\Sigma_{n}$ is the known covariance matrix of $M B_{n}$ and $\underline{\sim}=\underline{Q}$ when no loss has occurred. Though somewhat idealized, these assumptions can closely approximate materials balance behavior when error propagation information is good and nonmeasurement contributors to $\mathrm{MB}_{\mathrm{n}}$ are minor.

In partitioned form, $\mathrm{MB}_{\mathrm{n}}$ and $\Sigma_{\mathrm{n}}$ are decomposed as

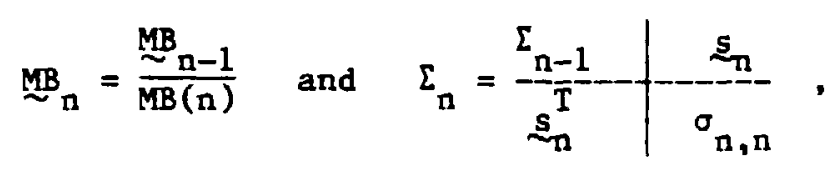

where $T$ denotes transposition and $\underline{s}_{n}$ is defined as indicated. The $j^{\text {th }}$ innovation $i(j)$ is

$$
i(j)=M B(j)-\underline{s}_{j}^{T} \Sigma_{j-1}^{-1}\left(\mathbb{M B}_{j-1}\right) .
$$

From multivariate normal theory, the expression $s_{j}^{T} \Sigma_{j-1}^{-1}\left(\mathbb{M B}_{j-1}\right)$ is the conditional expectation of $\mathrm{MB}(\mathrm{j})$ given (a) the previously observed $\mathrm{MBs},(b) \Sigma_{j}$, ard (c) no previous loss of material. The term "innovation" is sometimes informally replaced by "forecast error," "recursive residual," or, in the international safeguards literature, 
"MUF residual." Loosely speaking, $i(j)$ represents the error in predicting MB(j) based on (a), (b), and (c). The variance of the $j^{\text {th }}$ innovation $i(j), j=2,3, \ldots, n$, is

$$
v(j)^{2}=\sigma_{j, j}-\underline{s}_{j}^{T_{j-1}^{-1}} s_{j} .
$$

[Asides: (i) The first innovation is $\mathrm{i}(1)=M B(1)$ and its variance is $\sigma_{1,1}$. (ii) For computational purposes, Eqs. $(\mathrm{C}-1)$ and $(\mathrm{C}-2)$ are not efficient methods of deriving the $\{i(j)\}$ and $\{v(j)\}$.

\section{SEQUENTIAL TESTING}

The subject of sequential testing has been discussed elsewhere $\mathrm{Cl}^{\mathrm{C} 3}$ and need not be extensively elaborated here. Following from time series methodology, most sequential procedures monitor the innovation sequence. When no loss has occurred, the sequence of standardized innovations $\{\mathrm{i}(\mathrm{j}) / \mathrm{v}(\mathrm{j})\}$ behaves as a sequence of independent, normally distributed random variables with mean zero and variance one. Such a sequence is sometimes called "white noise." When a loss of material has occurred, the standardized innovation sequence behaves as independent normals with variance one, but has nonzero mean. Innovations for materials balances observed before the onset of the first loss(es) have zero mean, whereas innovations for materials balances observed after the onset of the first loss(es) generally have nonzero means.

In essence, the problem of sequential testing for materials loss reduces to observing the standardized innovation sequence in near real time and determining whether that sequence is consistent with white noise. Numerous procedures for making this determination have been put forth in the literature (see Refs. $\mathrm{C} 1-\mathrm{C} 3$ ). As invariably is the case in multivariate decision problems, no single procedure is best for all possible situations. Thus, two philosophies generally evolve: a first is to choose a test that performs well for some case(s) of interest but may perform poorly for other cases, and a second is to choose a test that has good overall properties but is nonoptimal for specific cases. 
A test procedure in the spirit of the second philosophy follows from standard CUSUM techniques. Attributed to Page, ${ }^{\mathrm{C} 4}$ the one-sided decision procedure monitors the statistic

$$
P_{j}^{+}=\max \left\{P_{j-1}^{+}+i(j) / v(j)-k, 0\right\},
$$

where $p_{0}=0$ and $k \geq 0$ is a threshold of the test. If, at any time during the monitoring, $P_{j}$ exceeds a threshold $h>0$, the materials balance sequence is deemed significant and an alarm is generated. Page's test can be viewed as a series of sequential probability ratio tests ${ }^{\mathrm{C} 5}$ and has been found to perform well. In addition, graphical techniques common to regression ${ }^{\mathrm{C}, \mathrm{C} 6}$ are useful in data analysis.

Test thresholds can be established on a variety of considerations. If a fixed number of materials balances are to be monitored, as when sequential testing is desired to provide near-real-time feedback between shutdowns of a process, thresholds can be chosen to provide a desired false-alarm rate. Alternatively, as in quality control where a sequence is observed continuously and does not have a natural beginning or end, thresholds can be chosen to give desired run-length properties, such as an average of one false alarm per $\mathrm{N}$ observations. Generally, threshold values cannot be determined analytically. Good approximations to thresholds (and to detection sensitivities) have been considered in the literature ${ }^{\mathrm{C} 7-\mathrm{C} 10}$; simulation can also be used.

Another issue in threshold determination is the number of materials balance closures. Unfortunately, the improved timeliness offered by numerous closures is not "free." In maintaining a fixed overall false-alarm rate, there is a tradeoff between the number of balances monitored and the detection probability. Arriving at the desired tradeoff can be somewhat subjective.

Thresholds derived for the normal distribution appear to be relatively robust. Though little formal work has appeared, innovations are similar to residuals in an ordinary regression and tend to be supernormal. ${ }^{\mathrm{Cll}}$ Thresholds for CUSUMs of such quantities should behave in near-normal fashion. 


\section{REFERENCES}

C1. R. Avenhaus, R. Beedgen, and D. Sellinschegg, "Test Procedures to Detect a Loss of Material in a Sequence of Balance Periods," Kernforschungszentrum Karlsruhe report KfK-3935 (1985).

C2. T. P. Speed and D. Culpin, "Evaluation of Techniques in Nuclear Materials Accountancy," SIROMATH Pty Ltd report (May 1985).

C3. R. R. Picard, "NRCPAGE Applications Manual," Los Alamos National Laboratory report LA-10638-M (NUREG/CR-4497) (April 1986).

C4. E. S. Page, "Continuous Inspection Schemes," Biometrika 41, 100-115 (1954).

C5. R. A. Khan, "On Cumulative Sum Procedures and the SPRT With Applications," Journal of the Royal Statistical Society B 46, 79-85 (1984).

C6. J. S. Galpin and D. M. Hawkins, "The Use of Recursive Residuals in Checking Model Fit in Linear Regression," The American Statistician 38, 94-105 (1984).

C7. D. Brook and D. Evans, "An Approach to the Probability Distribution of Cusum Run Length," Biometrika 59, 539-549 (1972).

C8. E. Yashchin, "On a Unified Approach to the Analysis of Two-Sided Cumulative Sum Schemes with Headstarts," Advances in Applied Probability 17, 562-593 (1985).

C9. M. Franklin, "Wiener Process Approximation to Determine False Alarm Rate and Detection Sensitivity of the One Sided Page's Test Applied to Sequential MUF Analysis," ISPRA Technical Note 1.05.04.81.92 (1981).

C10. B. J. Jones, "Near Real Time Accountancy: Calculation of the Parameters Used in Pages Test," ESARDA Bulletin 7, 19-22 (1984).

C11. R. D. Cook and S. Weisberg, Residuals and Influence in Regression (Chapman and Hall, New York, 1982). 


\title{
APPENDIX D
}

\section{BEHAVIOR OF THE (MUF-D) STATISTIC}

by

\author{
R. R. Picard
}

In this appendix, generic aspects of the (MUF-D) statistic are addressed. We review principles underlying the distribution theory and find that elements of sampling can interact with the effects of measurement errors to produce different types of behavior. When the inspector's sample size and/or the number of falsified items is small, the (MUF-D) statistic can be distinctly nonnormal. In other cases, the assumption of normality is approximately valid.

\section{THE SAMPLING MECHANISM}

For illustration, consider the case where a single stratum of items is being verified. Suppose that the stratum consists of $\mathbf{N}$ items, of which $\mathbf{n}$ items are randomly selected by the inspector for measurement. Also suppose that the operator's data for $m$ of the $\mathbf{N}$ items have been falsified; the corresponding items are designated "falsified items."

A first important component of (MUF-D) concerns the sampling distribution, the distribution of the number of falsified items among the inspector's sample. Intuitively, it is clear that the inspector will see, "on the average," the same portion of falsified items in his sample as exists in the population. However, variability about that average can take many forms.

Neglecting mathematical details, the probability that the inspector selects

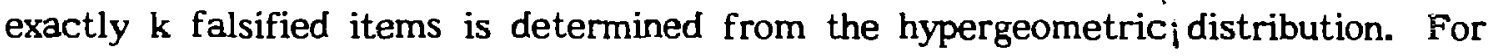
example, let the stratum consist of $\mathbf{N}=1000$ items, of which $\mathbf{n}=8$ are randomly selected by the inspector. When $\mathrm{m}(\mathrm{m}=500,50,950,200)$ items are falsified, the probabilities that the inspector samples exactly $\mathbf{k}$ falsified items are depicted in the histograms of Figs. D-1 through D-4. 


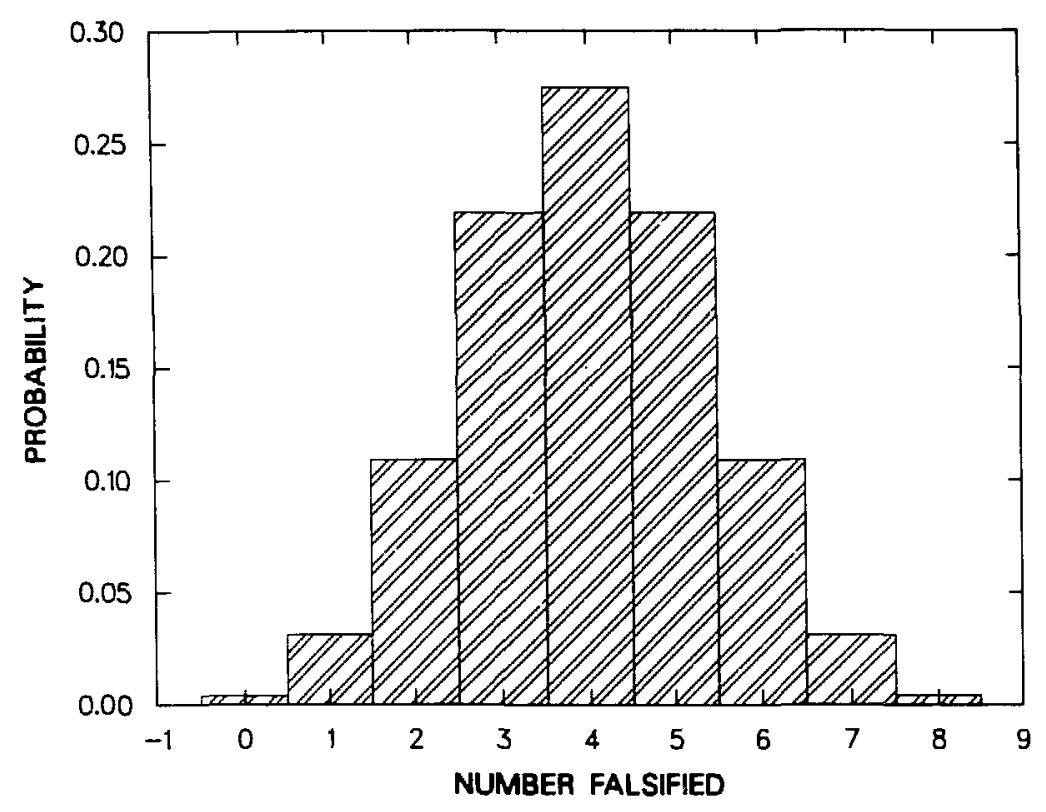

Fig. D-1. Histogram for the distribution of the number of falsified items among the inspector's samples of 8 items when 500 of the 1000 items are falsified.

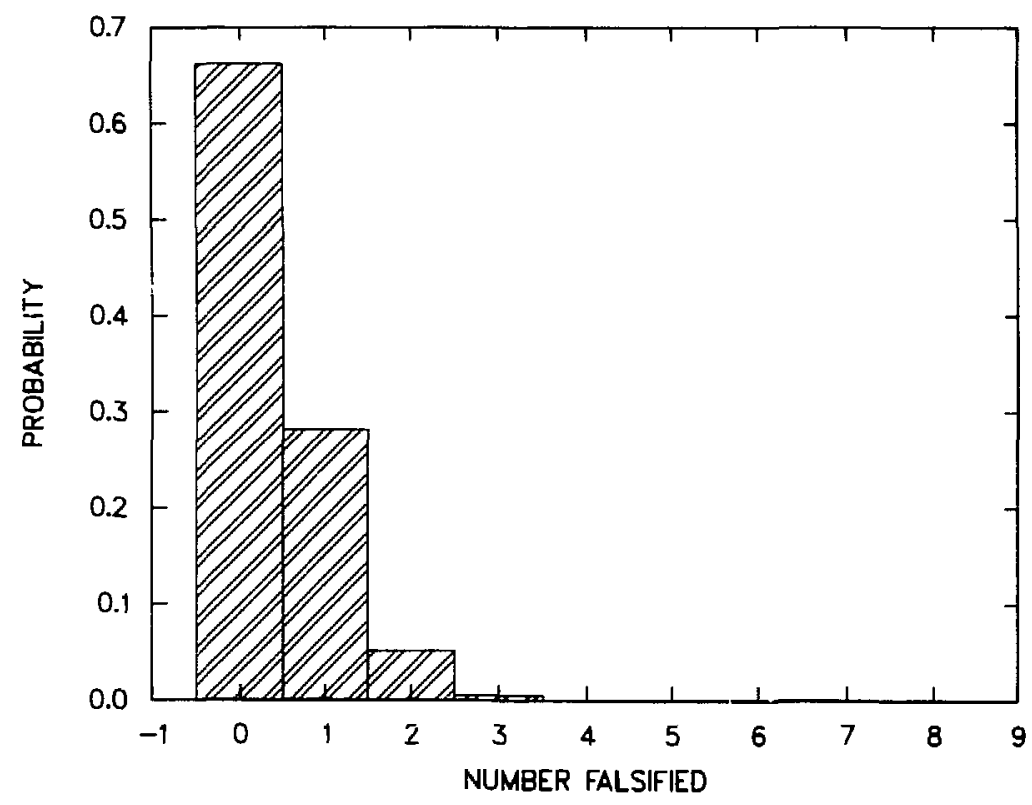

Fig. D-2. Histogram for the distribution of the nımber of falsified items among the inspector's samples of 8 items when 50 of the 1000 items are falsified. 


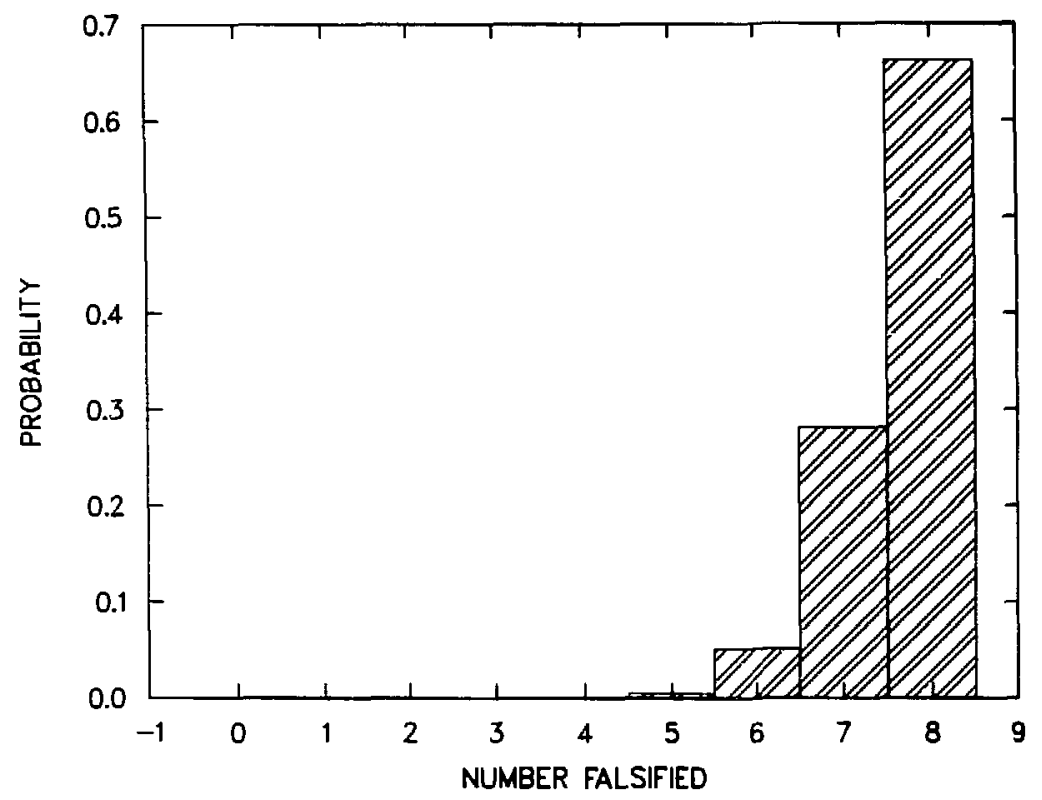

Fig. D-3. Histogram for the distribution of the number of falsified items among the inspector's samples of 8 items when 950 of the 1000 items are falsified.

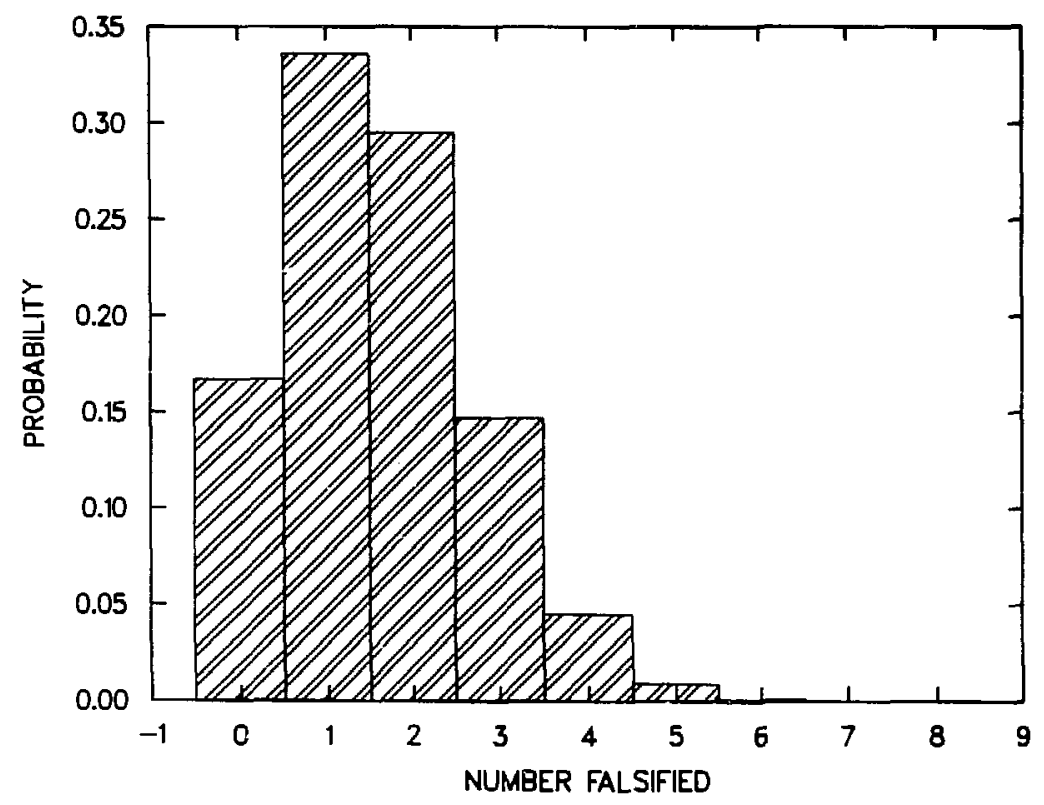

Fig. D-4. Histogram for the distribution of the number of falsified items among the inspector's samples of 8 items when 200 of the 1000 items are falsified. 
For the case where 500 of the 1000 items are falsified, the inspector can expect, on average, $*$ of his 8 sampled items to be falsified. As shown in Fig. D-1, variation around the average has a sym. netric shape somewhat similar to the normal distribution. It is unlikely--less than 1 chance in 250--that the inspector will have no falsified items among his sample.

Figure D-2 depicts the case where 50 of the 1000 items are falsified. Here, there is a $66 \%$ chance that the inspector's sample fails to include a falsified item; the chance of his sample including $k$ items declines as a function of $k$. Figure $D-3$, For the case where 950 of 1000 items are falsified, is the mirror image of Fig. D-2.

In one additional case of interest, Fig. D-4 shows the situation when 200 of 1000 items are falsified. Note that the distribution is skewed, with a "tail" to the right.

\section{u. EXTRAPOLATION, GOAL QUANTITES, AND THE D STATISTIC}

The D statistic estimates the total falsification in the operator's reported data. As the first step in the process, the inspector's measurements are compared with the corresponding values reported by the operator. Extrapolating the observed difference to the $\mathbf{N}$ items in the stratum yields the $\mathrm{D}$ statistic.

In the simplest case, there is only one measured value per item (as opposed, say, to a mass and concentration for which the inspector can verify either or botn). Let $\bar{d}$ be the average difference, operator minus inspector, for the $n$ sampled items. Then $D$ is simply $\pm N \bar{d}$, where the "plus" or "minus" depends on the sign of the falsification (for example, minus if the stratum corresponded to input transfers).

Because of the simple random sampling and the (presumed) unbiased measurements, the expected value of $\mathrm{D}$ is equal to the total faisification for the $\mathbf{N}$ items in the stratum. However, variability around the expected value can take several forms, depending on the situation. To illustrate, suppose for the moment that all measured values were perfect. In other words, the operator reports each item's actual value or, in the case of falsification, its falsified value. The inspertor sees each sampled item's actual value.

Figures D-5 through D-8 correspond to the scenarios of Figs. D-1 through D-4 and show the distributions of the D statistic when a goal quantity of $8 \mathrm{~kg}$ is falsified uniformly over the $\mathrm{m}$ falsified items. Bars in the histograms are narrow to indicate 


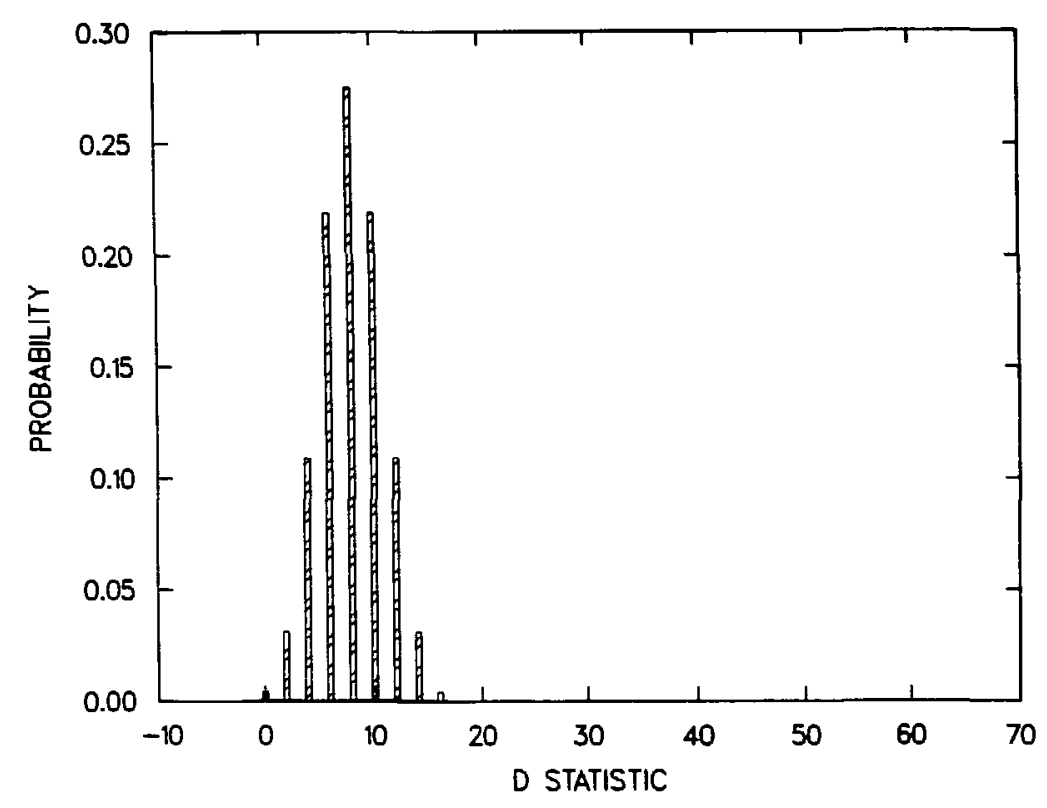

Fig. D-5. Histogram for the distribution of the D statistic given the scenario of Fig. D-1 when there are no measurement errors.

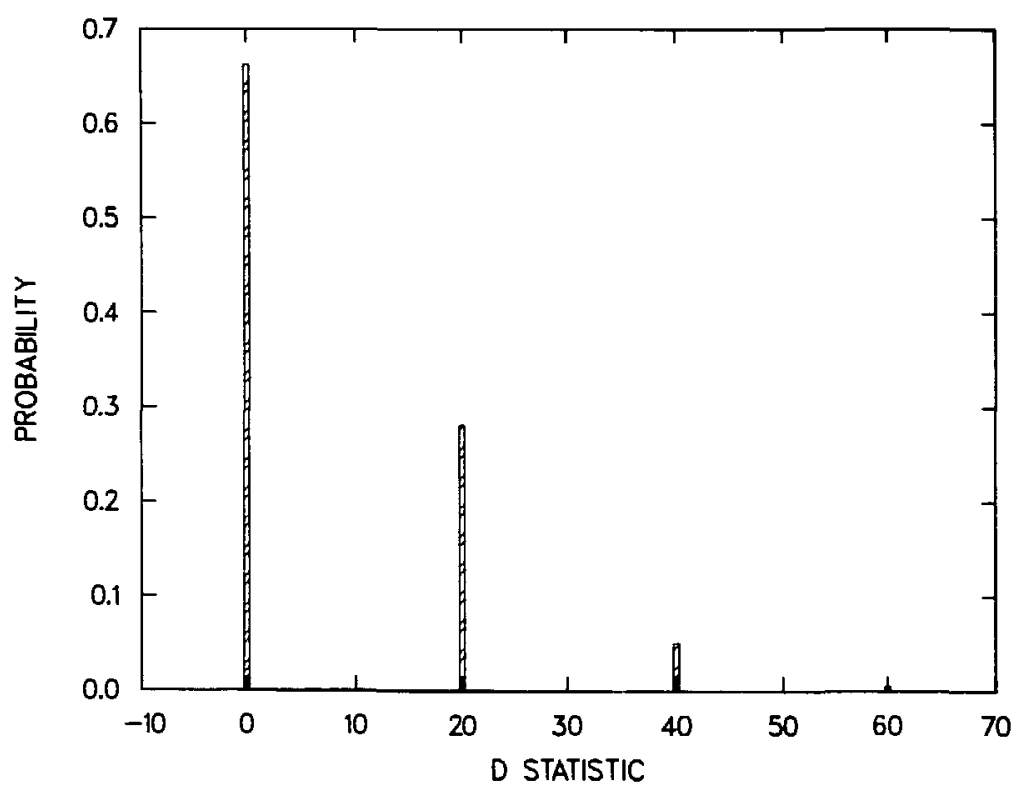

Fig. D-6. Histogram for the distribution of the D statistic given the scenario of Fig. D-2 when there are no measurement errors. 


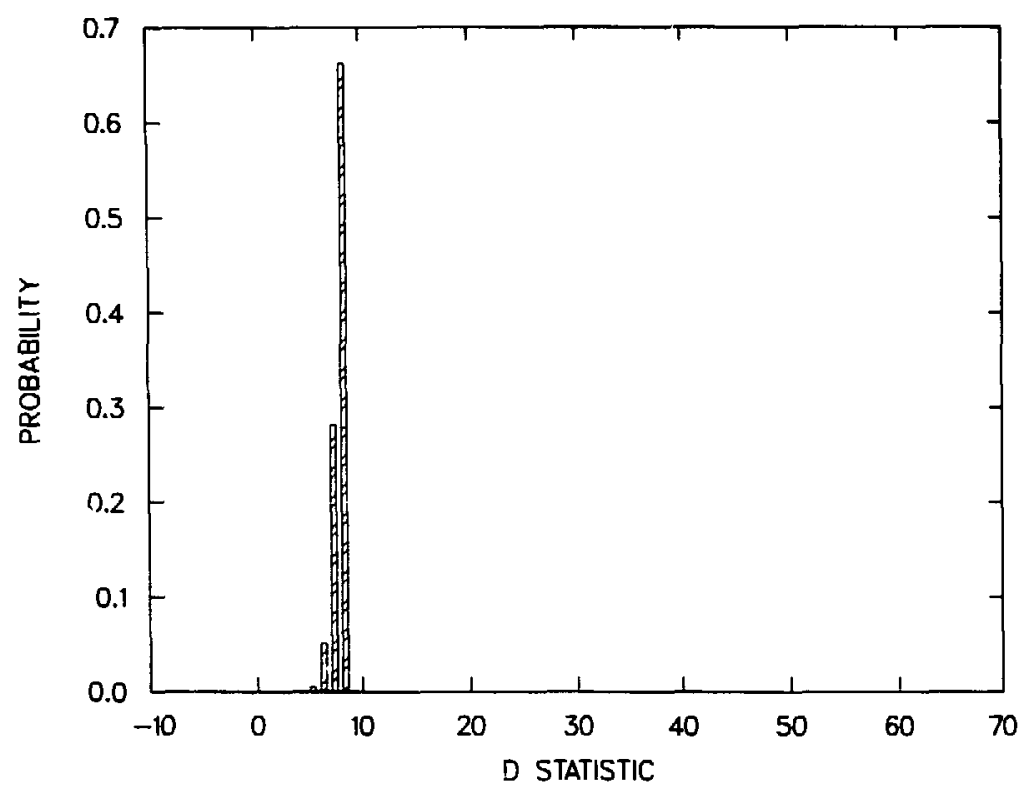

Fig. D-7. Histogram for the distribution of the D statistic given the scenario of Fig. D-3 when there are no measurement errors.

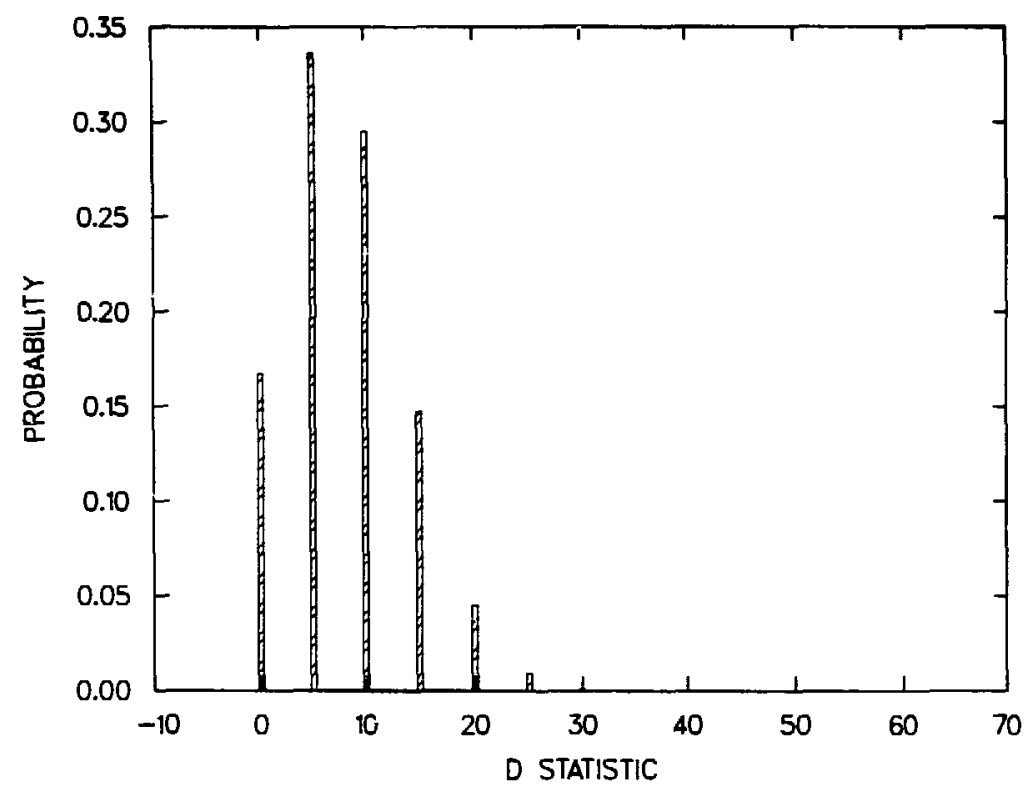

Fig. D-8. Histogram for the distribution of the D statistic given the scenario of Fig. D-4 when there are no measurement errors. 
that the values of the D statistic are exactly as shown with no measurement error. The value of $D$ depends on the goal quantity, $8 \mathrm{~kg}$, and the number of falsified items in the inspector's sample:

$8 \mathrm{~kg}$ total falsification in the stratum

implies

$8 / \mathrm{m} \mathrm{kg}$ falsification per falsified item

implies

$\bar{d}=j(8 / m) / n$ average falsification per item in the inspector's

sample consisting of $j$ falsified ar $d n-j$ unfalsified items

$$
\begin{gathered}
\text { implies } \\
D= \pm N \bar{d}= \pm 8 \mathrm{Nj} / \mathrm{nm} \mathrm{kg} .
\end{gathered}
$$

In the examples of Figs. D-5 through D-8, the D statistic can take on 9 distinct values, depending on whether the inspector's sample of 8 items contains $j=0,1$, $2, \ldots, 8$ falsified items.

Note also from Figs. D-5 through D-8 that the 9 distinct values of $D$ are each separated by the amount $8 \mathrm{~N} / \mathrm{nm} \mathrm{kg}$, roughly equal to $1000 / \mathrm{m} \mathrm{kg}$ when 8 of the 1000 items are sampled. When the number of falsified items $\mathrm{m}$ is small, the falsification per item is large and the distinct values of $\mathrm{D}$ are far apart, as in Fig. D-6. Conversely, small falsifications mean that distinct values of $D$ are much closer, as in Fig. D-7.

\section{MEASUREMENT ERRORS}

Figures D-5 through D-8 reflect the distribution of D insofar as it depends on the sampling component--that is, on the number of falsified items that happen to be sampled by the inspector. Ir practice, of course, measurement errors also play a role. Basically, this role is to "broaden the peaks" of the sampling component. See Franklin ${ }^{\mathrm{D} 1}$ for a more mathematical discussion.

In the simplest example, all items in the stratum are falsified by the same amount. For $8 \mathrm{~kg}$ spread uniformly over 1000 items, $8 / 1000 \mathrm{~kg}$ per item is involved. 
No matter which 20 items are sampled by the inspector, the sampling yields $\bar{d}=$ $8 / 1000$ and $D=8$. In other words, the sampling component corresponds to a histogram with a single bar at $8 \mathrm{~kg}$. Presence of normally distributed measurement errors leads to a situation similar to that in Fig. D-9, where the observed $D$ is normally distributed. The amount of broadening of the single peak depends on the magnitude of the measurement uncertainties of the operator and inspector.

If the sampling component of the distribution were nearly normal, as in Fig. D-5, then effects of measurement noise produce a normal-like shape for the observed D whose width is greater than that from either the sampling component or the measurement uncertainties alone. If the number of falsified items in the stratum is relatively large, this type of behavior is common.

Nonnormal shapes can also occur. Formally, D has contaminated normal distribution, although measurement noise may obscure this structure in a histogram. If the bars of the histogram for the sampling component are sufficiently far apart compared with measurement noise, the distribution for the observed $D$ is visibly multimodal. A skewed distribution can also arise. When the bars of the histogram for a skewed sampling component are close together compared with measurement noise, the result is a smoothed version of the sampling component. Examples of nonnormal behavior are provided in the next section.

\section{IV. (MUF $\left.{ }^{*}-D\right)$ FOR THE MOX LINE}

In the scenarios of Sec. $\mathrm{V}$ of the text, falsification covers the entire diversion. The operator:s MUF is, by design, equal to zero plus the effects of the operator's measurement errors. Thus, the distribution of $\left(\mathrm{MUF}^{*}-\mathrm{D}\right)$ for a given stratum resembles that of $\mathrm{D}$ alone.

Figures D-9 through D-11 illustrate three of the generic types of $\left(M_{U F}{ }^{*}-D\right)$ behavior. Figure D-9 corresponds to loss scenario 3 for $\$ 10,000 /$ month resource availability as described in Sec. $\mathrm{V}$ of the text, where all items in each stratum are falsified. The distribution of $\left(\mathrm{MUF}^{*}-\mathrm{D}\right)$ is centered around the actual falsification, $8 \mathrm{~kg}$, and the variability is the result of measurement errors alone. 


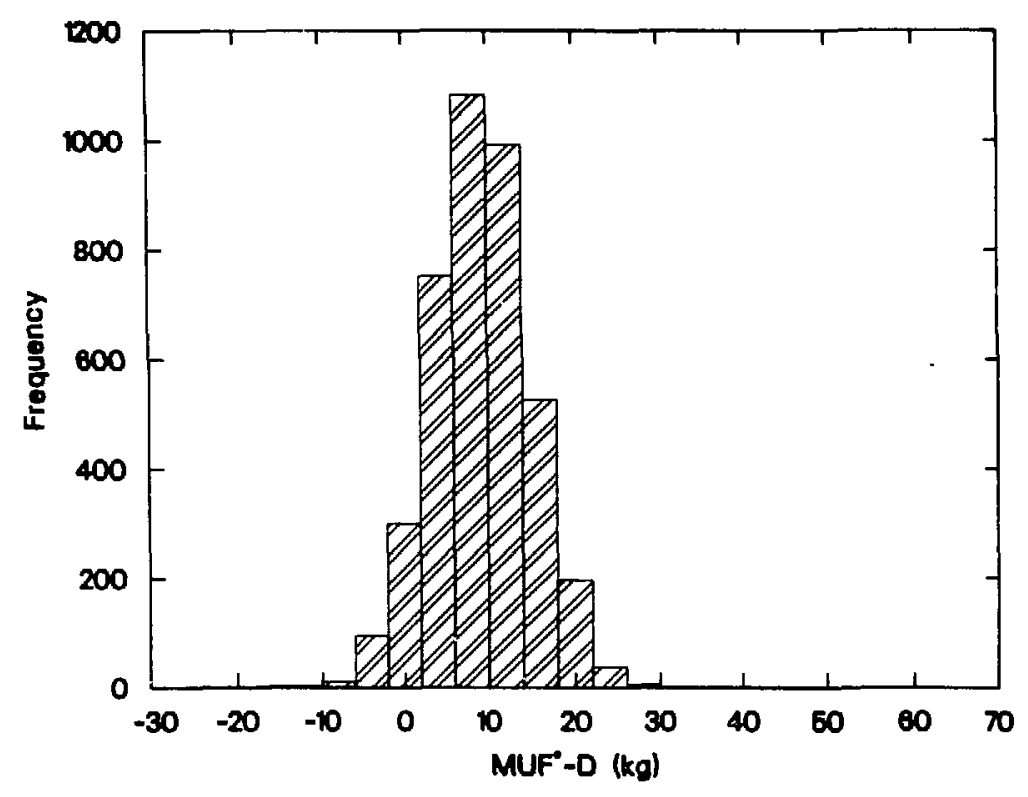

Fig. D-9. Histogram of the observed (MUF $\left.{ }^{*}-D\right)$ for scenario 3 at $\$ 10,000 /$ month (see Table XII).

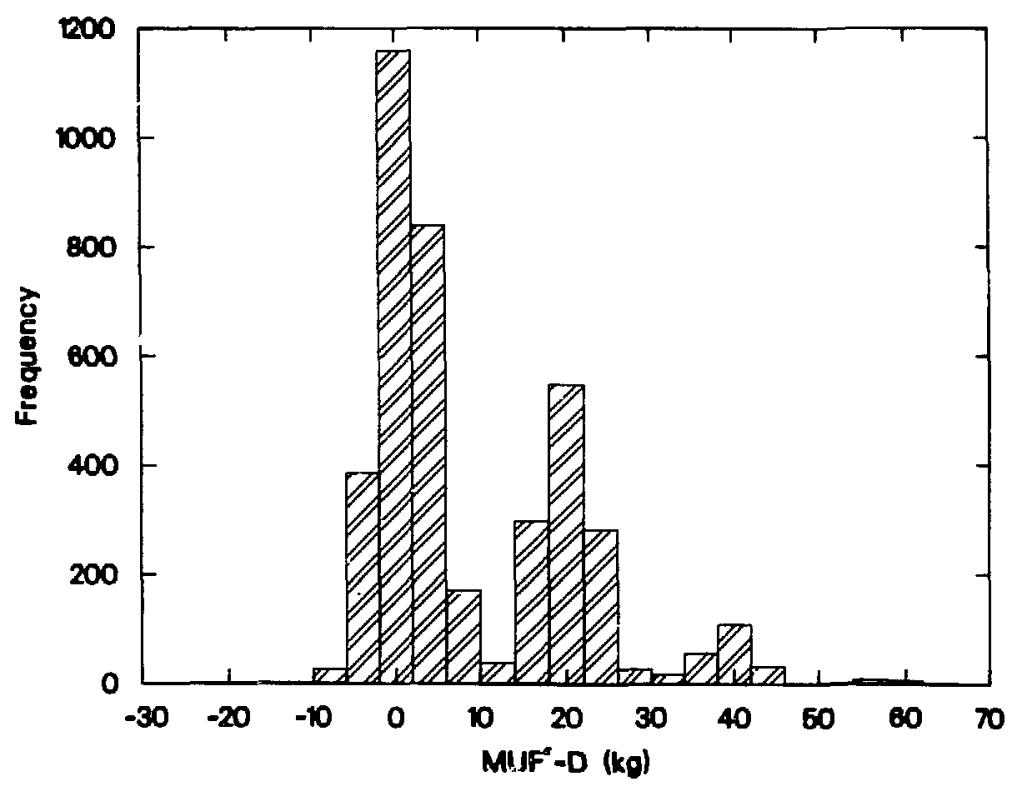

Fig. D-10. Histogram of the observed (MUF $\left.{ }^{*}-D\right)$ for scenario 6 at $\$ 35,000 /$ month (see Table XII). 


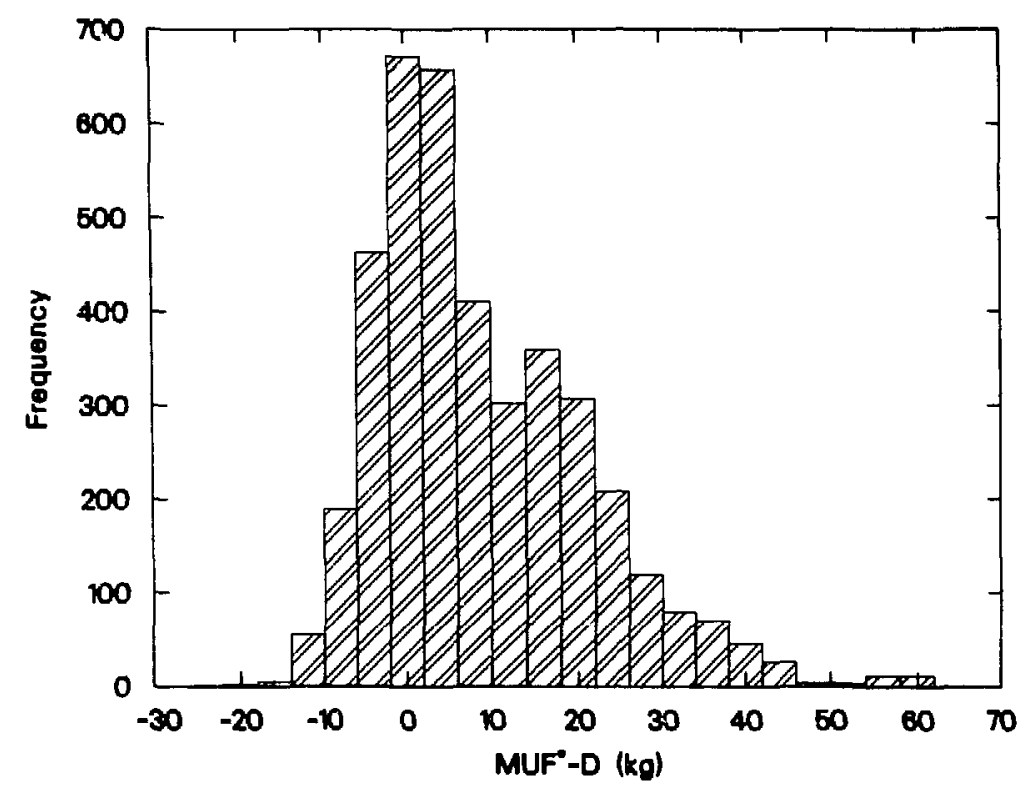

Fig. D-11. Histogram of the observed $\left(M_{U F}{ }^{*}-D\right)$ for scenario 7 at $\$ 10,000 /$ month (see Table XII).

Figure D-10 illustrates a multimodal case--scenario 6 at $\$ 35,000 /$ month resource allocation. Only a small portion of the items in two strata are falsified, and the inspector samples a small number of those items. Measurement errors are comparatively small, producing the multimodal shape, similar to what would be expected for a sampling regime analogous to that in Fig. D-6. Figure D-11 corresponds to loss scenario 7 at $\$ 10,000 /$ month, yielding a skewed distribution, similar to what would be expected for a sampling regime analogous to that in Fig. D-8.

Figures D-9 through D-1l demonstrate that when inspector resources are limited and when the number of falsified items is small, (MUF ${ }^{*}-\mathrm{D}$ ) is nonnormally distributed owing to the impacts of sampling. It is not adequate in such cases to approximate detection probabilities using analytical expressions for standard deviations together with a normality assumption; simulation is the simplest correct alternative. The normality assumption is, however, quite reasonable when the number of falsified items is large and the inspector's sample size is not too small. Other formulas applicable to special cases (Ref. D2, p. 37) are not strictly valid here because of the nonadditive error structures and the nonnormality introduced by multiplying concentration and mass measurements. Partial verification (for example, the inspector measures an item's concentration but not its mass) is an additional complicating factor, leading away from direct use of the hypergeometric function. 


\section{DIVERSION STRATEGIES}

From the standpoint of a potential adversary, there are two simple strategies: one is to defeat the sampling and the other is to defeat the measurement sensitivity. That is, if the number of falsified items is small, then an inspector could reasonably fail to sample any of them; alternatively, if falsified amounts are small, the falsifications could be easily obscured by measurement noise. Of course, compromise versions of the simple strategies are possible, and to some extent the situation is similar to that considered by attributes/variables sampling plans for inventory verification.

An intelligent adversary will choose a strategy based on the inspector's sampling scheme and on measurement uncertainties. As cases in point: if $100 \%$ of the items in a stratum are to be verified, it makes no sense to pursue large falsifications in that stratum; if measurement errors for a particular stratum are small, other strata are more attractive, all other things being equal.

Note: the potential adversary need not falsify data for the stratum from which he diverts material. Instead, falsification could occur from strata offering the least chances of detection. For example, if input tran r rs were poorly measured and not frequently sampled by the inspector, falsification of the associated items might be attractive. Material could then be diverted from elsewhere in the process, and the operator's materials balance would not indicate anomalous activity.

\section{REFERENCES}

D1. M. Franklin, "The Sampling Distribution of the D Statistic," Nuclear Materials Management XIII (Proceedings Issue), 135-142 (1984).

D2. R. Avenhaus, Material Accountability: Theory, Verification, and Applications (John Wiley \& Sons, Inc., New York, 1977). 